\title{
Modelos Neurais para Regressão em Séries Temporais
}

\author{
Thiago Ildeu Albuquerque Lira
}

\author{
DISSERTAÇÃO APRESENTADA AO \\ INSTITUTO DE MATEMÁTICA E EsTATÍSTICA \\ DA UNIVERSidAde de SÃo PAUlo \\ PARA OBTENÇÃO DO TÍTULO DE \\ MESTRE EM CIÊNCIAS
}

Programa: Ciência da Computação

Orientador: Prof. Dr. Marcelo Finger

Durante o desenvolvimento deste trabalho o autor recebeu auxílio financeiro da CAPES

São Paulo

8 de Setembro de 2020 



\title{
Modelos Neurais para Regressão em Séries Temporais
}

\author{
Thiago Ildeu Albuquerque Lira
}

Esta versão da dissertação contém as correções e alterações sugeridas pela Comissão Julgadora durante a defesa da versão original do trabalho, realizada em 8 de Setembro de 2020.

Uma cópia da versão original está disponível no Instituto de Matemática e Estatística da Universidade de São Paulo.

Comissão Julgadora:

- Prof. Dr. Marcelo Finger (orientador) - IME-USP

- Prof. Dr. Vanderley Moacir John - POLI-USP

- Prof. Dr. Roberto Lotufo - UNICAMP 
Autorizo a reprodução e divulgação total ou parcial deste trabalho, por qualquer meio convencional ou eletrônico, para fins de estudo e pesquisa, desde que citada a fonte. 


\section{Agradecimentos}

Aos meus pais Karla e Lira e irmão Thomaz pela força e apoio sempre, apesar de eu não conseguir explicar direito o meu trabalho. Aos amigos Paula e Felipe e Vívian pela ajuda nos momentos difíceis. A minha prima Júlia que ouviu a explicação da minha pesquisa muito mais vezes do que é saudável.

Probability. You know, like two to one, three to one, five to four against. It said two to the power of one hundred thousand to one against. That's pretty improbable, you know. - Douglas Adams 



\section{Resumo}

Thiago Ildeu Albuquerque Lira. Modelos Neurais para Regressão em Séries Temporais: . Dissertação (Mestrado). Instituto de Matemática e Estatística, Universidade de São Paulo, São Paulo, 2017.

Dada a crescente importância da predição de resistência compressiva do cimento para um uso mais eficiente de recursos na indústria, literatura recente busca analisar quais modelos estatísticos podem auxiliar o processo indústrial. Esse trabalho documenta a aplicação de técnicas de Deep Learning Bayesiano para a geração de predições temporais robustas e confiáveis para a resistência compressiva do cimento. Os resultados mostram que técnicas de Inferência Bayesiana para modelos de Aprendizado Profundo promovem um ganho sensível de acurácia para o problema de predição de RC, com o benefício adicional das características probabilísticas das predições, tornando-as mais seguras para o possível uso no chão de fábrica.

Palavras-chave: Deep Learning. Séries Temporais. Inferência Bayesiana. 



\begin{abstract}
Thiago Ildeu Albuquerque Lira. Neural Models for Regression on Time Series: . Thesis (Masters). Institute of Mathematics and Statistics, University of São Paulo, São Paulo, 2017.

Given the increasing importance of the prediction of the cement compressive strength for a more efficient use of resources on the industry, recent literature has been experimenting with statistical models to aid the industrial process. This thesis studies the application of Bayesian Deep Learning techniques to achieve robust and accurate predictions of the compressive strength. The results show that Bayesian Inference techniques applied to Deep Learning models promote a sensible increase of accuracy for the problem of CS predition, with the additional benefit gained from the probabilistic nature of the predictions, making them more suitable to be used on the factory floor.
\end{abstract}

Keywords: Deep Learning. Bayesian Inference. Time Series 



\section{Lista de Abreviaturas}

ML Aprendizado Automático (Machine Learning)

DL Aprendizado Profundo (Deep Learning)

MSE Erro Quadrático Médio (Mean Squared Error)

ABNT Associação Brasileira de Normas Técnicas

URL Localizador Uniforme de Recursos (Uniform Resource Locator)

IME Instituto de Matemática e Estatística

USP Universidade de São Paulo 


\title{
Lista de Símbolos
}

\author{
$\theta \quad$ Vetor de parâmetros de algum modelo Estatístico \\ $\mathcal{N}\left(x ; \mu, \sigma^{2}\right) \quad$ A variável aleatória $x$ é distribuída normalmente com média $\mu$ e desvio-padrão $\sigma$ \\ $f(x ; \theta)$ Função em $x$ parametrizada por $\theta$
}




\section{Lista de Figuras}

1.1 Representação das Diversas Etapas da produção de Cimento (AgEncy, 2009) 3

2.1 Em uma nomenclatura simplificada, a lei de Bayes descreve a maneira de como podemos atualizar nossa crença no evento $A$ dado a observação do evento $B$. Para isso usa-se a nossa probabilidade a priori $P(A)$ e a verossimilhança $P(B \mid A)$. O denominador $P(B)$ é uma constante de normalização que frequentemente não precisa ser calculada diretamente.

2.2 Um exemplo de Rede Neural no contexto dos dados de produção de cimento 16

2.3 Diagrama representando o uso do modelo de regressão linear janelado na prática para os dados. . . . . . . . . . . . . . . . . . . 19

2.4 Grafo de Computação de uma RNN genérica (Goodfellow et al., 2016) 20

2.5 Diagrama com uma exemplificação do uso de modelos sequenciais baseados em RNNs para a predição de resistência RC28. . . . . . . . . . . . . 22

2.6 Diagrama da arquitetura de uma LSTM . . . . . . . . . . . . . . . . 23

2.7 Diagrama de Rede Encoder-Decoder. Modificado de (Neural Machine Translation - Tutorial ACL 2016 s.d.) . . . . . . . . . . . . . . . 24

2.8 Representacão do uso de Dropout em uma rede neural . . . . . . . . . . 25

2.9 Modelo durante o Treinamento (LAPTEV et al., 2017) . . . . . . . . . . . . 27

2.10 No módulo de inferência usamos uma rede neural simples para gerar predições a partir da codificação aprendida durante o pré-treino (LAPTEV et al., 2017) . . . . . . . . . . . . . . . . .

2.11 Para o treino, o modelo é guiado por anotações reais de valores passados da série alvo $y$ e as variáveis independentes $x$. Usamos o estado $h$ da rede LSTM a cada iteração temporal para calcular $\mu$ e $\sigma$. Esses valores são então usados no calculo da verossimilhança $p(y \mid \mu, \sigma)$, o valor que é minimizado.

2.12 Se desejarmos prever mais de um valor da série-alvo $y$ no futuro. O modelo é realimentado com os valores amostrados de $y^{*}$ e a rede continua a realizar predições. . . . . . . . . . . . . . . . . . . . . 
3.1 Porcentagem de dados faltantes por variável para dados de Expedição de Cimento. Cada coluna azul indica a porcentagem do total de dias contemplados pela planilha que contém dados dessa variável. . . . . . . . .

3.2 Distribuição das distâncias entre entradas subsequentes dos dados de Expedição de Cimento, antes da reamostragem. Grande parte das entradas da planilha estão distantes de 1 dia. Porém uma quantidade significativa tem 3 dias de intervalo (sem dados no meio). Para o trabalho será necessário preencher esses dias faltantes. . . . . . . . . . . . . . . .

3.3 Correlograma dos índices de resistência compressiva. A diagonal mostra a distribuição de cada variável. Como esperado, RC28 tem uma correlação maior com ensaios mais recentes (i.e. RC7) do que com RC1. . . . . . . .

4.1 Divisão do dataset para a saída RC28, os pontos verdes foram usados para treino e os pontos azuis usados para validação. . . . . . . . . . . . . .

4.2 Predições nos dados de validação nos experimentos com modelos não-

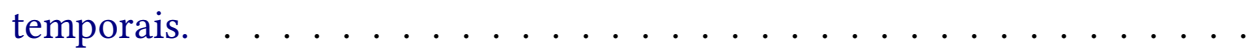

4.3 Valores reais plotados contra os valores previstos para análise da distribuição aprendida por cada modelo. Os modelos de Aprendizado de Máquina possuem flutuações altas na distribuição das predições, frutos de viés. . .

4.4 Os dados são divididos em 11 datasets separados, onde temos por dataset 11 meses usados para treino e os últimos dias do ano para validação. . . .

4.5 Predições no período de teste para cada período de validação pelo modelo

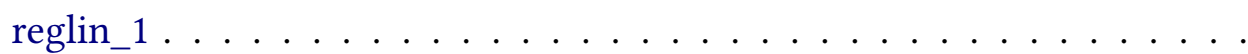

4.6 Predições no período de teste para cada período de validação pelo modelo

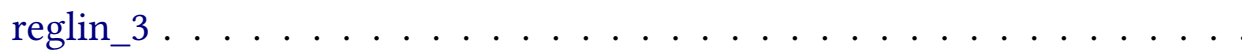

4.7 Predições no período de teste para cada período de validação pelo modelo

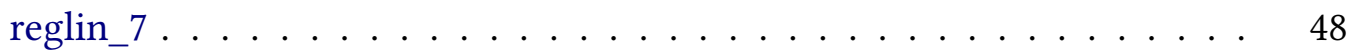

4.8 Predição do RC28 para todos os dados de validação para o modelo DeepAR_1 49

4.9 Predição do RC28 para todos os dados de validação para o modelo DeepAR_3 50

4.10 Predição do RC28 para todos os dados de validação para o modelo DeepAR_7 50 


\section{Lista de Tabelas}

2.1 O conjunto de variáveis usado para cada um dos modelos, de maneira análoga ao apresentado no trabalho Tsamatsoulis, 2015 . . . . . . . . .

2.2 Intervalos de tempo usados como dados de treinamento e predição dos modelos. . . . . . . . . . . . . . . . . . . . . . 18

3.1 Variáveis presentes nos dados de expedição de cimento cedidos pela Intercement . . . . . . . . . . . . . . . . . .

3.2 Tabela mostrando as correlações de Pearson entre cada uma das variáveis

4.1 RMSE por modelo. . . . . . . . . . . . . . . . . . . . 44

4.2 O conjunto de variáveis usado para cada um dos modelos, de maneira análoga ao apresentado no trabalho Tsamatsoulis, 2015 . . . . . . . .

4.3 Valores agregados de RMSE para os modelos de Regressão Linear Dinâmica. Como esperado, o erro decresce a medida que mais variáveis são incorporadas ao modelo. O modelo corrigido tem o menor erro quadrático.

4.4 Riscos-quantílicos para os percentis de $50 \%$ e $90 \%$ das distribuições das predições para os modelos de DL Bayesiano. Os menores riscos-quantílicos são fornecidos pelos modelos DeepAR e Uber. . . . . . . . . . . . . . . .

4.5 Coberturas das predições probabilísticas para os quantis de 50\% e 90\% de confiança. Apesar de o modelo Deep Factors ser capaz de fornecer a maior cobertura, veremos mais adiante que a média das predições possui erros sensívelmente maiores que dos outros modelos. . . . . . . . . . . . . .

4.6 Valores do RMSE para cada modelo nos horizonte de predição de $24 \mathrm{~h}$ e 7 dias. Os modelos Uber e DeepAR são sensívelmente melhores que os modelos Deep Factors. O modelo DeepAR gera predições mais estáveis para todas as tarefas de aprendizado. 
4.7 Valores do RMSE para cada modelo nos horizonte de predição de $24 \mathrm{~h}$ e 7 dias. Os modelos DeepAR consistentemente geram melhores predições agregando valores previstos por 7 dias após a implementação do modelo em produção. . . . . . . . . . . . . . . . . . . . . . 52

1 Parâmetros do modelo Deep_AR . . . . . . . . . . . . . . . . . 54

2 Parâmetros do modelo Deep Factors . . . . . . . . . . . . . . . . . . . 54

3 Parâmetros do modelo Encoder-Decoder-Forecaster . . . . . . . . . . . . 54 


\section{Sumário}

1 Introdução 1

1.1 Motivação . . . . . . . . . . . . . . . . . . . . . . 1

1.2 Produção de Cimento . . . . . . . . . . . . . . . . . . . . 3

1.2.1 Índice de Resistência de Cimento Portland . . . . . . . . . . . . . . 4

1.3 Objetivos ........................ 4

1.4 Organização do Trabalho . . . . . . . . . . . . . . . . . . 4

2 Conceitos Teóricos $\quad 7$

2.1 O problema de predição de RC como Regressão . . . . . . . . . . . . . 7

2.1.1 Séries Temporais . . . . . . . . . . . . . . . 7

2.1.2 O problema de predição de RC como Regressão de Série Temporal 8

2.2 Estatística Frequentista e Estatística Bayesiana . . . . . . . . . . . . . . 9

2.3 Aprendizado Automático . . . . . . . . . . . . . . . . . 9

2.3.1 A Experiência . . . . . . . . . . . . . . . . . . . 10

2.3.2 A Performance . . . . . . . . . . . . . . . . . . 11

2.3.3 Método da Máxima Verossimilhança . . . . . . . . . . . . . . . 11

2.3.4 Erro Quadrático Médio . . . . . . . . . . . . . . . . . . . . . 12

2.3.5 Inferência Bayesiana . . . . . . . . . . . . . . . . . 12

2.3.6 Métrica de Acurácia para Modelos de Série Temporal . . . . . . . 14

2.4 Abordagem Não-Temporal para predição de RC28 . . . . . . . . . . . . . 15

2.4.1 Redes Neurais (Arquitetura Feed-Forward) . . . . . . . . . . . . . 15

2.5 Modelos Sequenciais para predição de RC28 . . . . . . . . . . . . . . 17

2.5.1 Janela Móvel com Filtragem Exponencial para RC28 _ . . . . . . 17

2.5.2 Rede Neural Recorrente . . . . . . . . . . . . . . . . . . 20

2.5.3 Consumo de dados de Cimento para Modelos baseados em RNNs 22

2.5.4 Modelo DeepAR . . . . . . . . . . . . . . . . . . . 30

2.5.5 Modelo com Deep Factors . . . . . . . . . . . . . . . . . . 32

2.6 Correlação entre Variáveis . . . . . . . . . . . . . . . . . . . 34

2.7 Normalização Min-Max . . . . . . . . . . . . . . . . . . . . . . . . 35 
3 Estudo dos Dados $\quad 37$

3.1 Preparo dos Dados . . . . . . . . . . . . . . . . . 37

3.1 .1 Dados faltantes . . . . . . . . . . . . . . . 37

3.2 Reamostragem dos dados . . . . . . . . . . . . . . . . 38

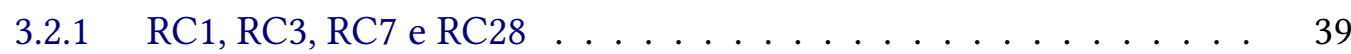

4 Resultados Experimentais $\quad 41$

4.1 Modelos de Aprendizado de Máquina . . . . . . . . . . . . . . . . . . . . . . 41

4.2 Metodologia . . . . . . . . . . . . . . . . . 41

4.2.1 Divisão dos dados entre treino e validação . . . . . . . . . . . . 41

4.3 Modelos de Séries Temporais . . . . . . . . . . . . . . . . . . 44

4.4 Metodologia . . . . . . . . . . . . . . . . . 44

4.4.1 Divisão dos dados entre treino e validação . . . . . . . . . . . . . 45

4.4.2 Regressão Linear Dinâmica com Filtragem Exponencial . . . . . 46

4.5 Modelos de Deep Learning Bayesianos . . . . . . . . . . . . . . . . 49

5 Conclusões $\quad 53$

5.1 Sugestões para Pesquisas Futuras . . . . . . . . . . . . . . . 53

$.1 \quad$ Hiper-parâmetros dos Modelos de Deep Learning . . . . . . . . . . . . . 54

$\begin{array}{ll}\text { Bibliografia } & 55\end{array}$ 


\section{Capítulo 1}

\section{Introdução}

A predição da resistência compressiva do cimento (CCS) é reconhecida como de extrema importância para a indústria da construção civil, pois essa capacidade é um dos fatores para avaliar a qualidade do cimento (TAFFESE e Sistonen, 2017). O CCS após 28 dias da produção do cimento (RC28) é escolhido como um parâmetro regulatório em normas de construção. Dado que os custos anuais de manutenção de estruturas são da ordem de bilhões de dólares, métodos estatísticos para a predição dessa quantidade ainda na fase de fabricação ganham ainda mais importância para o funcionamento mais eficiente da indústria. Nota-se também que essa indústria representa grande parte das emissões de $\mathrm{CO}_{2}$ na atmosfera (Agency, 2009).

Esse trabalho é uma colaboração entre a empresa Intercement, o Laboratório de Lógica, Inteligência Artificial e Métodos Formais do IME-USP e o Departamento de Construção Civil da POLI-USP. Foram apresentados 10 anos de dados de diversas etapas da produção de cimento do complexo de Cajati, uma das plantas da empresa. Esse trabalho estuda a possibilidade do uso de modelos computacionais e estatísticos modernos em dados produzidos diariamente nas fábricas, para a tomada de decisões na operação da fábrica.

\subsection{Motivação}

Trabalhos recentes aplicam técnicas estatísticas para predição de RC28 em amostras de cimento num contexto laboratorial (GARCíA-CASILLAs et al., 2007; ZHANG et al., 2012). Nosso objetivo é estender a metodologia para levar essas análises da operação da fábrica, com dados colhidos na operação diária que já possam entregar resultados imediatos para a ação dos operadores.

O trabalho (Tsamatsoulis, 2014) propõe uma metodologia de aplicação de técnicas de regressão linear para predição de RC28 cujos parâmetros são recalculados sempre que um novo valor RC28 é amostrado pelo laboratório. Nossa contribuição é similar, por meio de um tratamento completo dos dados providenciados na operação da fábrica como séries temporais i.e. dados indexados por anotações de tempo. 
Por muitas décadas o estado da arte desse tipo de análise temporal centrou-se nos processos ARIMA, com a metodologia Box-Jenkins (Asteriou e HALL, 2016). Esses modelos têm uma excelente capacidade estatística e interpretabilidade. Mas essa família de modelos possui suas limitações: ela falha em modelar relações não-lineares nos dados (GREEN et al., 2011) e muitos processos reais tendem a ser não-lineares por natureza. Esses modelos também têm dificuldade de incorporar variáveis independentes (i.e. além da própria série alvo, RC28 no caso desse trabalho) à série temporal nas predições (LAPTEV et al., 2017).

A modelagem de séries temporais tem se beneficiado pelo desenvolvimento de novos métodos de Aprendizado de Máquina (ML), e mais recentemente de Aprendizado Profundo (DL). Modelos de DL diferem de abordagens estatísticas clássicas por serem orientados a dados (Goodfellow et al., 2016). Esses modelos não necessitam de seleção de atributos, ou seja, é minimizada a necessidade de especialistas para a escolha de variáveis, e esse tipo de modelo também não assumem muito sobre a distribuição geradora dos dados, como por exemplo a família ARIMA, que requisita do engenheiro de dados a especificação da sazonalidade e estacionariedade dos dados (Asteriou e HALL, 2016). Redes Neurais são capazes de aprender sozinhas diversas características dos dados sem necessidade de intervenção. Alguns trabalhos uniram a flexibilidade de redes neurais com a robustez de métodos ARIMA (Robles et al., 2008; Khashei e BIJARI, 2010), criando soluções melhores que qualquer um desses modelos sozinho. Porém, uma das arquiteturas de DL mais presentes atualmente em análise de séries temporais são as Redes Neurais Recorrentes. Esses modelos já foram usados com melhores resultados do que métodos clássicos para prever séries temporais de demanda de energia elétrica e de carros em um aplicativo de corridas popular (MARINo et al., 2016; LAPTEV et al., 2017). Outro benefício de modelos baseados em redes neurais são a capacidade de modelar não-linearidades complexas e também de não assumir independência estatística entre as variáveis de entrada (GoOdFELlow et al., 2016).

Um método de estimação adequado às incertezas do processo deve ser capaz de prever o sensível nível de imprecisão e incerteza que ocorre no processo industrial, refletindo assim as condições reais observadas na fábrica. A estatística bayesiana oferece técnicas mais robustas para a modelagem de incerteza (BARBER, 2012). E num contexto em que possuímos muitos dados, técnicas de DL também podem ser aplicadas com um desenvolvimento bayesiano para a propagação de erro e cálculo de incertezas (LAPTEV et al., 2017; Y. GAL, 2016). Outro benefício de técnicas propostas recentemente na área de predição de séries temporais com DL consiste no uso de diversas séries temporais similares para o treinamento de uma única tarefa, e.g. históricos de consumo de energia elétrica de milhares de residências diferentes. Métodos clássicos como ARIMA têm dificuldade na incorporação de diversas séries temporais para a resolução de uma só tarefa, sendo necessário que os modelos sejam treinados individualmente para cada série temporal e então agregados para a tomada de decisões. Trabalhos como (LAPTEV et al., 2017; Flunkert et al., 2017; MADDIX et al., 2018) propõe métodos robustos e com parâmetros compartilhados (i.e. globais) no uso de um número arbitrário de séries temporais para uma mesma tarefa. 


\subsection{Produção de Cimento}

Nessa seção a produção de cimento será brevemente descrita, usando como base a Figura 1.1:

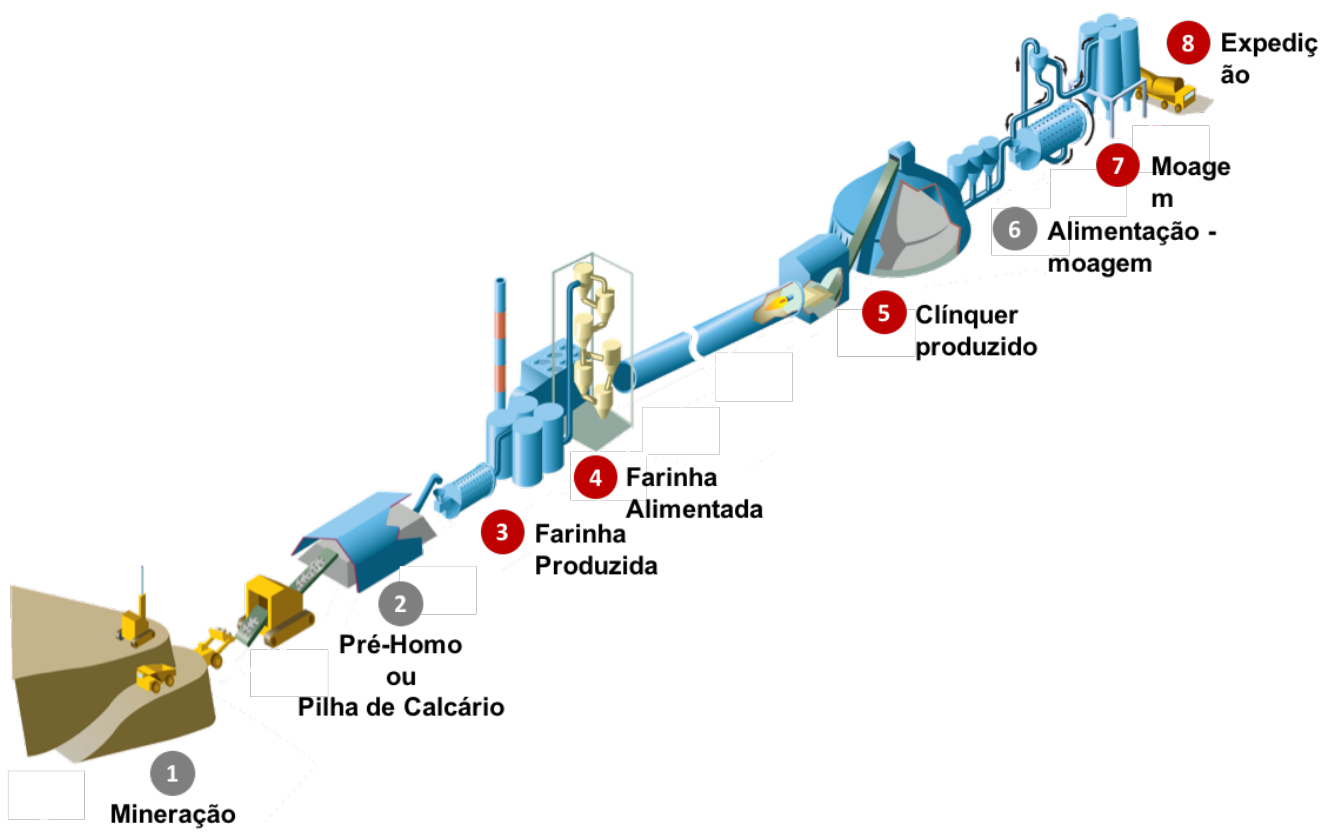

Figura 1.1: Representação das Diversas Etapas da produção de Cimento (AGENCY, 2009)

As etapas de produção serão explicadas por número como indicado na imagem:

1 Depósitos ricos em carbonato de cálcio são minerados para extração desse químico. Normalmente a planta é próxima da mina.

2 O material extraído é triturado em pedaços de até $10 \mathrm{~cm}$ de diâmetro. Diferentes materiais são misturados ao resultado da tritura, de modo a manter a composição química desejada.

3 A farinha crua é pré-aquecida para que depois no forno as reações químicas aconteçam mais rápido.

$4 \mathrm{O}$ carbonato de cálcio é transformado em $\mathrm{CaO}$ por meio de reações químicas.

$5 \mathrm{O}$ material é introduzido ao forno, atingindo temperaturas de até $1450^{\circ} \mathrm{C}$, transformando a farinha em clínquer. O clínquer é resfriado após a saída do forno.

6 O clínquer então é misturado com outros componentes que formam o cimento.

7 A mistura é então moída.

8 O material é empacotado, estocado e eventualmente expedido para entrega. 
Os dados de interesse nesse projeto são medições de diversos parâmetros em meio ao processo de fabricação do cimento. Eles são divididos em diversas planilhas para diferentes etapas da produção de cimento, são elas, em ordem no processo:

- Cimento Cru

- Farinha

- Clinquér

- Produção de Cimento

- Expedição de Cimento (Saco e Granel)

Dado que não existe uma maneira trivial de combinar dados de partes diferentes do processo (é muito difícil acompanhar o mesmo lote de cimento/matéria prima em partes diferentes do processo), as análises serão feitas em cima dos dados de Expedição de Cimento.

\subsection{1 Índice de Resistência de Cimento Portland}

A propriedade que iremos tentar prever usando nossos modelos será a resistência compressiva do cimento. A resistência de uma amostra de cimento é ensaiada em intervalos determinados de dias após a sua confecção. Essas informações são anotadas nos dados com os nomes de $R C n$, com $n$ sendo a idade da amostra em dias. Esses índices possuem a unidade de MPa, i.e. quilopascal. Valores usuais desse ensaio são RC1, RC3, RC7 e RC28 (o mais relevante para as normas).

\subsection{Objetivos}

O problema de negócio da produção de Cimento envolve poder decidir o mais rápido possível e sem gastos desnecessários com experimentos e matéria prima o cimento que será vendido. Para isso é necessário estimar o resultado do ensaio de RC28 o quanto antes. Esse trabalho busca usar as técnicas mais recentes de Deep Learning Bayesiano para a geração de predições probabilísticas com incertezas calibradas a ponto de ser possível tomar desições baseadas em dados no chão de fábrica. Substituindo então o uso de modelos empíricos e opiniões de especialistas para cada lote que é produzido.

\subsection{Organização do Trabalho}

No Capítulo 2, apresentamos os conceitos de Aprendizado de Máquina, estatística frequentista e bayesiana, estimadores, métricas de acurária e uma breve explicação de cada modelo usado. É feita também uma introdução à inferência bayesiana, e uma possível aproximação numérica dessa técnica. No Capítulo 3 são apresentadas características gerais dos dados e testes estatísticos sobre propriedades desses. No Capítulo 4 enumerados as 
transformações necessárias para usar os dados em modelos sequenciais e resultados de predições e métricas de acurária de todos os modelos. No Capítulo 5 são apresentadas direções para pesquisa futura e palavras finais. 



\section{Capítulo 2}

\section{Conceitos Teóricos}

\subsection{O problema de predição de RC como Regressão}

Para cada lote de cimento presente nos dados, possuímos resultados do ensaio de RC28 (o objetivo de predição), bem como de ensaios químicos (e.g. concentração de $\mathrm{Al}_{2} \mathrm{O}_{3}$ ) e mesmo ensaios de resistência compressiva mais rápidos (RC1, RC3 e RC7). Usaremos esses resultados de ensaios químicos, bem como RC1, RC3 e RC7 como entrada para modelos estatísticos buscando modelar o nosso alvo RC28.

Seja um modelo de regressão $f$, uma predição de RC28 usará o vetor de entrada $\mathbf{x}$ e uma matriz de parâmetros $\theta$ :

$$
R \hat{C} 28_{i}=f\left(\mathbf{x}_{i} ; \theta\right)
$$

A função será encontrada por métodos de aprendizado que serão explicados ao longo desse trabalho. Nota-se que para essa modelagem outros valores de RC28 (e suas variáveis) temporalmente próximos do i-ésimo não são usados. Dada a natureza temporal do processo industrial, trabalhos recentes passaram a incomporar o histórico de entradas e saídas na análise, obtendo resultados mais robustos (Tsamatsoulis, 2015).

É importante notar que o objetivo de todos os modelos desse trabalho será sempre a predição de RC28, nunca de outra grandeza.

\subsubsection{Séries Temporais}

Séries temporais são dados indexados em ordem temporal. Formalmente, podemos representar uma série temporal como uma lista de números ou vetores ordenados por índices naturais (KoOpMANs, 1974).

$$
X=\left\{x_{0}, x_{1}, x_{2} \ldots x_{T}\right\}
$$


Ou ainda, especificando o conjunto de índices, $T$, que representa o período completo onde os dados foram amostrados:

$$
X=\left\{x_{t}, t \in T\right\}
$$

Os índices da série temporal não precisam representar momentos igualmente espaçados no tempo, embora isso seja necessário para diversas técnicas de modelagem e análise (Siami-Namini e NAmin, 2018).

\subsubsection{O problema de predição de RC como Regressão de Série Temporal}

Os dados da produção de cimento, como ensaios de resistência e composição química são anotados temporalmente, então podemos escolher modela-los como uma série temporal. A tarefa de regressão se torna então prever as próximas anotações desses dados num horizonte de tempo futuro finito. Na tarefa de aprendizado será usada a série temporal alvo $Y$, dos índices $R C_{28}$ de resistência compressiva, $Y=\left\{y_{t}, t \in T\right\}$. Também serão usadas séries temporais de variáveis presentes na produção de cimento, $\left\{\mathbf{x}_{t}, t \in T\right\}$, onde cada $\mathbf{x}_{t} \in \mathbb{R}^{K}$, cada dimensão $k$ representando uma variável diferente. Cada $\mathbf{x}_{t}$ terá a forma $\left\{\mathrm{Al}_{2} \mathrm{O}_{3 t}, I P_{t} \ldots\right\}$ dependendo das variáveis escolhidas para cada modelo. Uma listagem completa das variáveis presentes nos dados é apresentada na Tabela 3.1.

O treinamento será realizado com valores dessas séries nas anotações de tempo no intervalo $[1, T]$. Seja $T$ o último dia em que se possui dados da variável alvo RC28. Um modelo de aprendizado supervisionado $f \operatorname{com}$ parâmetros $\theta$ poderá ter duas formas, uma auto-regressiva e uma sem auto-regressão, i.e. a própria série alvo usada no problema de predição.

$$
R \hat{C} 28_{T: T+F}=f\left(R C 28_{T-29-W: T-29}, \mathbf{x}_{T-W: T+F} ; \theta\right)
$$

E para a versão sem auto-regressão:

$$
R \hat{C} 28_{T: T+F}=f\left(\mathbf{x}_{T-W: T+F} ; \theta\right)
$$

A função é parametrizada por $W$ e $F$, respectivamente o tamanho da janela de dados do passado que o modelo irá usar para as predições e o número de dias para o qual o modelo irá gerar predições no futuro. Uma limitação adicional do problema de predição de RC28 é que o último valor de RC28 que pode ser usado está presente 29 dias no passado, característica incorporada nos modelos auto-regressivos, atrasando a série alvo em 29 dias. O objetivo de treinamento é encontrar parâmetros $\theta$ para que essa função seja o mais assertiva possível. 


\subsection{Estatística Frequentista e Estatística Bayesiana}

Como nesse trabalho serão usados métodos de inferência Bayesiana aplicados a Aprendizado Automático, cabe uma breve elaboração das diferenças entre as duas principais interpretações da estatística (Goodfellow et al., 2016).

Historicamente, a estatística era pensada como um conjunto de métodos de contagem, idealizados na realidade de jogos de azar e outras atividades de natureza aleatória. Mesmo após a estatística ter sido formalizada ao lado de outros ramos da matemática em uma base sólida, resta a interpretação de seus métodos e objetos de estudo (probabilidades) quando aplicados em problemas reais. Duas dessas são as mais usadas em Ciencia da Computação: A Frequentista e a Bayesiana.

A interpretação frequentista é relacionada às origens da estatística, entendendo probabilidades como contagens de eventos em um espaço amostral pré-definido, supondo que no limite, se pudéssemos repetir experimentos infinitas vezes, chegaríamos ao valor real de alguma probabilidade ou estatística. Métodos frequentistas fazem estimativas pontuais (i.e. não aleatórias) e tratam os dados como uma entre muitas possíveis realizações de uma distribuição de probabilidade desconhecida, porém fixa.

No caso bayesiano, entende-se a probabilidade como um grau de confiança. Começamos experimentos com uma distribuição a priori que representa o conhecimento sobre algum fenômeno antes de observados os dados (uma distribuição de probabilidade assim como as usadas em métodos frequentistas). Usa-se então a lei de Bayes para atualizar o nosso conhecimento a priori com a evidência dada pela observação dos dados, gerando assim uma probabilidade a posteriori.

$$
P(A \mid B)=\frac{P(B \mid A) P(A)}{P(B)}
$$

Figura 2.1: Em uma nomenclatura simplificada, a lei de Bayes descreve a maneira de como podemos atualizar nossa crença no evento $A$ dado a observação do evento $B$. Para isso usa-se a nossa probabilidade a priori $P(A)$ e a verossimilhança $P(B \mid A)$. O denominador $P(B)$ é uma constante de normalização que frequentemente não precisa ser calculada diretamente.

No campo de Aprendizado Automático, as duas maneiras de se gerar predições são estimadores frequentistas (Seção 2.3.3) e inferência Bayesiana (seção 2.3.5).

\subsection{Aprendizado Automático}

O campo de Aprendizado Automático (Machine Learning - Aprendizado Automático) é um ramo da Ciência da Computação que utiliza métodos estatísticos e adaptativos para criar sistemas que possam aprender a realizar uma determinada tarefa através de dados. Um problema de Aprendizado Automático possui as seguintes partes (GoodfELlow et al., 2016): 
- A tarefa $T$, no caso dos dados da produção de cimento, um problema de regressão. Onde desejamos estimar valores numéricos a partir de uma matriz de dados $X$ e suas anotações numéricas $Y$.

- Uma métrica de performance $P$, que define a distância entre as predições do modelo e os dados de treinamento. A teoria por trás desses métricas será explicada na seção 2.3.2.

- A experiência $E$, que define qual tipo de informação o modelo poderá usar durante o treinamento. Explicaremos esse conceito a seguir.

\subsubsection{A Experiência}

Algoritmos de Aprendizado Automático podem ser divididos nas categorias de aprendizado supervisionado, não supervisionado e aprendizado por reforço (GooDFELLOW et al., 2016). Técnicas dos dois primeiros tipos serão usadas para os dados de produção de cimento.

\section{Aprendizado Supervisionado}

Aprendizado Supervisionado consiste, do ponto de vista estatístico, no aprendizado de uma distribuição de probabilidade do tipo $p(y \mid x)$. Uma regressão linear pode ser entendida como a distribuição do alvo $y, p(y \mid x)=\theta^{T} x+\epsilon=\mathcal{N}\left(\theta^{T} x, \sigma\right), \epsilon \sim \mathcal{N}(0, \sigma)$. Usaremos a notação $\epsilon \sim \mathcal{N}(0, \sigma)$ significando que a variável aleatória $\epsilon$ possui uma distribuição normal com média 0 e desvio-padrão $\sigma$. Esse ponto será melhor explorado na Sessão 2.3.3.

Dados vetores de entrada $x$ associados a uma anotação $y$, a tarefa consiste na busca de uma função dentro de uma família de funções que melhor generalize a relação entre $x$ e $y$. De modo que os modelos possam gerar anotações inéditas $y^{\prime}$ para dados $x^{\prime}$ nunca antes vistos.

\section{Aprendizado Supervisionado para Séries Temporais}

Desejamos modelar a distribuição de probabilidade das próximas anotações de $y$ até uma nova data $F+T, F \in \mathbb{N}$, condicionadas por uma janela de observações das diversas variáveis $x_{k}$ e do alvo $y$ no passado (MADDIx et al., 2018). Supõe-se que possuímos entradas das variáveis $x_{i}$ também no período de predição, i.e. no intervalo $[T, F]$.

$$
p\left(y_{T: F} \mid y_{1: T}, \mathbf{x}_{1: F}\right)
$$

A distribuição será buscada por meio de aprendizado supervisionado, onde os modelos serão alimentados com diversos pares de entradas, $\left(y_{t}, \mathbf{x}_{t: t+W}\right)$, onde $\mathbf{x}$ é um vetor que contém os valores de cada variável independente $x_{i}$, no instante de tempo $t$. Cada tupla de entrada contém $W$ entradas do vetor de entrada. O parâmetro $W$, o tamanho da janela de 
tempo consumida para gerar cada saída, é escolhido antes do treino e pode ser alterado na busca de uma melhor acurácia de predição.

\section{Aprendizado Não Supervisionado}

Para o caso de Aprendizado Não Supervisionado, mantendo a estrutura do exemplo anterior, desejaríamos então modelar uma distribuição do tipo $p(x)$, onde temos também diversos exemplos de vetores aleatórios $x$ e estamos estudando alguma propriedade importante dessa distribuição. Esse tipo de problema é mais comum em tarefas de Visão Computacional e NLP.

\subsubsection{A Performance}

A performance dos modelos de Aprendizado Automático é a quantificação da qualidade das predições frente a verdade desconhecida do fenômeno modelado. Claramente um modelo parametrizado possuirá algum erro de predição (GoodfEllow et al., 2016), e é esse erro que iremos diminuir com o aprendizado. O Risco de um modelo é o valor esperado do erro das suas predições (MURPHy, 2013). Como precisaríamos conhecer a distribuição real geradora dos dados para calcular esse valor, nos contentamos com o cálculo do Risco Empírico (Murphy, 2013), usado para avaliar a performance de um modelo. O Risco Empírico é calculado pela soma do Custo de uma predição do modelo para cada ponto datual. O custo irá capturar alguma noção de proximidade entre as predições do modelo e os valores reais. A ferramenta estatística frequentista mais usada para encontrar boas funções de custo é o método de máxima verossimilhança, explicado em detalhes na Sessão 2.3.3.

\subsubsection{Método da Máxima Verossimilhança}

Como explicado previamente na Sessão 2.3.1, Aprendizado Supervisionado consiste na busca de uma distribuição de probabilidade que explique as anotações em função das entradas (ou variáveis).

A verossimilhança é a medida da probabilidade do modelo, parametrizado com um determinado conjunto de parâmetros, ter gerado os dados. Em outras palavras gostaríamos de um modelo que tem uma alta probabilidade de ter gerado os dados observados. Usando um exemplo de aprendizado supervisionado onde desejamos modelar a distribuição $p(Y \mid X)$, o estimador de máxima verossimilhança é o que minimiza a equação:

$$
\theta_{M L E}=\underset{\theta}{\arg \max } p(Y \mid X ; \theta)
$$

Onde $p(Y \mid X ; \theta)$ é uma família de distribuições de probabilidade parametrizada por $\theta$ que modela o nosso problema de aprendizado, $\theta_{M L E}$ é o parâmetro que maximiza $p(Y \mid X)$, a verossimilhança. O objetivo de otimização não se altera se otimizarmos o logarítimo 
da verossimilhança, e essa mudança torna a otimização mais estável, visto que ao aplicar logarítmos em números pequenas estaremos então lidando com números maiores e com mais precisão. Podemos também, considerando os dados i.i.d., substituir a verossimilhança pelo somatório da verossimilhança de cada ponto datual.

$$
\theta_{M L E}=\underset{\theta}{\arg \max } \sum_{i=0} \log p\left(y_{i} \mid x_{i} ; \theta\right)
$$

Os custos que são otimizados no treinamento de modelos de Aprendizado Profundo são derivados do Método de Máxima Verossimilhança. Para regressão é comum se usar alguma medida de distância para ser minimizada, uma das mais usadas e que incorpora o conceito de máxima verossimilhança é o Erro Quadrático Médio.

\subsubsection{Erro Quadrático Médio}

O Erro Quadrático Médio é o Estimador de Máxima Verossimilhança caso consideremos um erro Gaussiano para o modelo. Sejam valores reais de anotação $Y$ e as predições de algum modelo de regressão $\hat{Y}$ :

$$
M S E=\sum_{i=1}^{n} \frac{\left(\hat{y}_{i}-y_{i}\right)^{2}}{n}
$$

$\hat{y}_{i}$ é uma função de $\theta$, os parâmetros do modelo. Podemos usar o gradiente dessa função de custo com respeito a $\theta$ e diretamente otimizar esses valores. Esse método, chamado de backpropagation é ubíquo para otimização de modelos de Aprendizado Profundo (GOODFELlow et al., 2016).

\subsubsection{Inferência Bayesiana}

O tratamento Bayesiano para modelos de Aprendizado Automático é bastante diverso do frequentista (GoodfEllow et al., 2016).

Pode-se considerar que diferença entre as duas escolas de pensamento está em onde se considera que a incerteza do problema modelado está presente: Para a interpretação bayesiana a incerteza está presente no modelo, as observações não são consideradas variáveis aleatórias, mas uma realidade observada. Para a estatística frequentista considerase que os dados de entrada são uma realização possível de uma distribuição desconhecida, e um modelo gera estimativas pontuais (MCELREATH, 2016).

Considerando-se que todos os parâmetros de um modelo estão contidos em um vetor $\theta$, em uma análise frequentista estima-se o "melhor valor" (checar Sessão 2.3.3) de $\theta$ e então todas as predições são feitas a partir desse valor. No caso Bayesiano se consideram toda a distribuição de possíveis valores de $\theta$ ao se fazer uma predição. E também se considera uma distribuição a priori de todos os parâmetros do modelo. Essa será atualizada pela Lei 
de Bayes em frente a evidência apresentada pelos dados (que não são mais considerados variáveis aleatórias, mas observadas).

Sejam $X, Y$ respectivamente entradas e anotações usadas no treinamento de um modelo, $x^{*}, y^{*}$ um par inédito de entrada e anotação (i.e. dados de teste) e $\theta$ os parâmetros dos modelos.

Usando a nomenclatura Bayesiana, $p\left(y^{*} \mid x^{*}, \theta\right)$ é a verossimilhança de uma nova predição do modelo e $p(\theta \mid X, Y)$ é a distribuição posterior dos parâmetros do modelo, obtida pela aplicação da lei de Bayes.

$$
p(\theta \mid X, Y) \sim p(Y \mid X, \theta) * p(\theta)
$$

Para obtermos a distribuição de uma nova predição do modelo devemos marginalizar os parâmetros $\theta$ usando a seguinte integral:

$$
p\left(y^{*} \mid x^{*}, X, Y\right)=\int p\left(y^{*} \mid x^{*}, \theta\right) p(\theta \mid X, Y) d \theta
$$

Para grande parte dos modelos de Aprendizado Automático a distribuição posterior $p(\theta \mid X, Y)$ é intratável (LAPTEv et al., 2017). Pode-se de definir uma outra distribuição $q(\theta)$, que pode ser otimizada por métodos numéricos para aproximar $p(\theta \mid X, Y)$. E então usando a distribuição variacional podemos calcular uma aproximação da distribuição das predições $q\left(y^{*} \mid x^{*}\right)$. A aproximação da equação a seguir depende de uma boa escolha de $q$.

$$
\begin{aligned}
p\left(y^{*} \mid x^{*}, X, Y\right) & \approx \int p\left(y^{*} \mid x^{*}, \theta\right) q(\theta) d \theta \\
& =q\left(y^{*} \mid x^{*}\right)
\end{aligned}
$$

Para aproximar $q$ da distribuição alvo usa-se o método da Inferência Variacional (BARbER, 2012). O objetivo $\mathcal{L}_{V I}$ na Equação 2.3 é sempre menor que $\log p(Y \mid X)$, e igual no limite em que $q(\theta)$ seja exatamente igual a $q(\theta \mid X, Y)$. Esse objetivo é chamado de Variational Lower Bound, e ele é derivado da distância KL entre $q$ e a distribuição alvo:

$$
\mathcal{L}_{V I}=\int q(\theta) \log p(Y \mid X, \theta) d \theta-K L(q(\theta)|| p(\theta)) \leq \log p(Y \mid X)
$$

A outra distância KL está presente no objetivo de otimização é a distância entre a distribuição a priori $p(\theta)$ e a distribuição aproximada $q(\theta)$ dos parâmetros do modelo. É importante notar que a Equação 2.3 é verdade para qualquer escolha de $q$. A otimização de $\mathcal{L}_{V I}$ buscará tornar essa aproximação o melhor possível. 


\section{Divergência KL}

A divergência KL, ou Kullback-Leibler, é uma medida de diferença entre duas distribuições de probabilidade (também chamada de Entropia Cruzada).

Essa medida pode ser definida pelo valor esperado da diferença logarítmica da probabilidade que os dados sejam observados em uma distribuição ou na outra (GoodfELlow et al., 2016).

Sejam duas distribuições de probabilidade $p$ e $q$, bem como uma matriz de dados $X$ :

$$
D_{K L}(p \| q)=\mathbb{E}[\log p(x)-\log q(x)]
$$

Ou em uma forma mais usual:

$$
D_{K L}(p \| q)=\sum_{i=1}^{N} p\left(x_{i}\right) \log \frac{p\left(x_{i}\right)}{q\left(x_{i}\right)}
$$

\subsubsection{Métrica de Acurácia para Modelos de Série Temporal}

Diferentemente da função de custo, a métrica de acurácia não é usada para guiar a otimização do modelo, mas para testar as predições frente a realidade e avaliar sua qualidade. Em particular, apenas o erro quadrático não é suficiente para mensurar a qualidade de predições probabilísticas. Para isso, usamos métricas que levam em consideração a distribuição das predições, e não apenas a sua média.

\section{Custo quantílico}

O custo quantílico (FLunkert et al., 2017) é usado na avaliação de performance de predições temporais.

Para uma predição com desvio-padrão $\sigma$, um quantil $q$ representa o valor que cobre $\rho \%$ da distribuição de probabilidade dessa predição.

Por exemplo, usando o quantil $\rho=0.9=90 \%$, podemos calcular quantos desviospadrões cobrem $90 \%$ dos valores presentes na distribuição. Assumindo distribuição normal das predições, com média $y^{*}$, para $\rho=0.9$, uma tabela $\mathrm{z}$ nos mostra que devemos usar 1.29 desvios-padrões:

$$
y^{*}(\rho=0.9)=y^{*}+1.29 \sigma
$$


Logo, $y^{*}(0.9)$ cobre $90 \%$ dos possíveis valores de predição feitos pelo modelo, levando em consideração o desvio-padrão.

Dado um quantil $\rho \in(0,1)$ um valor real $y_{t}$ e um quantil de previsão $y_{t}^{*}(\rho)$, define-se o custo quantílico por:

$$
Q \mathcal{L}_{\rho}\left(y_{t}, y_{t}^{*}(\rho)\right)= \begin{cases}2 \rho\left(y_{t}-y_{t}^{*}(\rho)\right) & \text { se } y_{t}-y_{t}^{*}(\rho)>0 \\ 2(1-\rho)\left(y_{t}^{*}(\rho)-y_{t}\right) & \text { se } y_{t}-y_{t}^{*}(\rho) \leq 0\end{cases}
$$

Esse valor é somado em todas as séries temporais $i$ no horizonte de predição representado pelos valores de $t$ e normalizado usando os valores da série temporal.

$$
p(\rho) Q L=\frac{\sum_{i, t} Q \mathcal{L}_{\rho}\left(y_{t}, y_{t}^{*}(\rho)\right)}{\sum_{i, t}\left|y_{i, t}\right|}
$$

Esse valor é bastante informativo quando as saídas dos modelos são distribuições de probabilidades. Esse valor nos informa o risco ponderado de um certo quantil da predição.

Se usarmos o quantil $\rho=0.5=50 \%$, p50QL, esse valor se torna a porcentagem absoluta média de erro (MAPE). Para $\rho=0.9=90 \%$, p90QL, será calculado o erro máximo esperado por $90 \%$ das predições.

\subsection{Abordagem Não-Temporal para predição de RC28}

\subsubsection{Redes Neurais (Arquitetura Feed-Forward)}

Redes neurais são aproximadores universais de funções (HoRnik et al., 1989). Dado um problema de classificação onde se deseja aprender uma função da forma $y=f^{*}(x)$, uma Rede Neural define um mapeamento $y=f(x ; \theta)$, onde $\theta$ é o vetor de parâmetros que serão aprendidos com o fim de minimizar a diferença entre a distribuição empírica e essa distribuição gerada pelo modelo. Essa diferença pode ser minimizada pelo método da verossimilhança, assim como elaborado na sessão 2.3.3.

O modelo neural é uma composição de funções que unem uma transformação linear e a aplicação de uma função não-linear $\sigma$ :

$$
f(x)=\sigma(W * x+b)
$$


Importante ressaltar que $W$ é uma matriz, assim como $x$ e $b$ são vetores.

A computação da saída de uma rede neural então pode ser escrita como:

$$
y=f_{n} \circ f_{n-1} \circ f_{n-2} \ldots f_{1}(x)
$$

Para uma rede neural de $n$ camadas, onde cada camada será uma função $f_{i}$ cujos parâmetros são $W_{i}$ e $b_{i}$. Portanto, para a i-ésima camada da rede sua saída será da forma:

$$
f_{i}(x)=a_{i}=\sigma\left(W_{i} * a_{i-1}+b_{i}\right)
$$

Onde $a_{i-1}$ é a saída da camada anterior, também chamada de ativação. A saída dessa camada é então a sua ativação $a_{i}$.

Vale notar que uma saída $y$ calculada por uma rede neural depende unicamente dos seus parâmetros e da entrada $x$. Isso não será verdade para os modelos sequenciais que também serão usados nesse trabalho, onde o estado interno de computação desses modelos é usado como entrada para uma próxima iteração (GoodfEllow et al., 2016).

Na Figura 2.2 mostramos como seria uma rede que usa os índices RC3 e RC7 para modelar como saída o índice RC28.

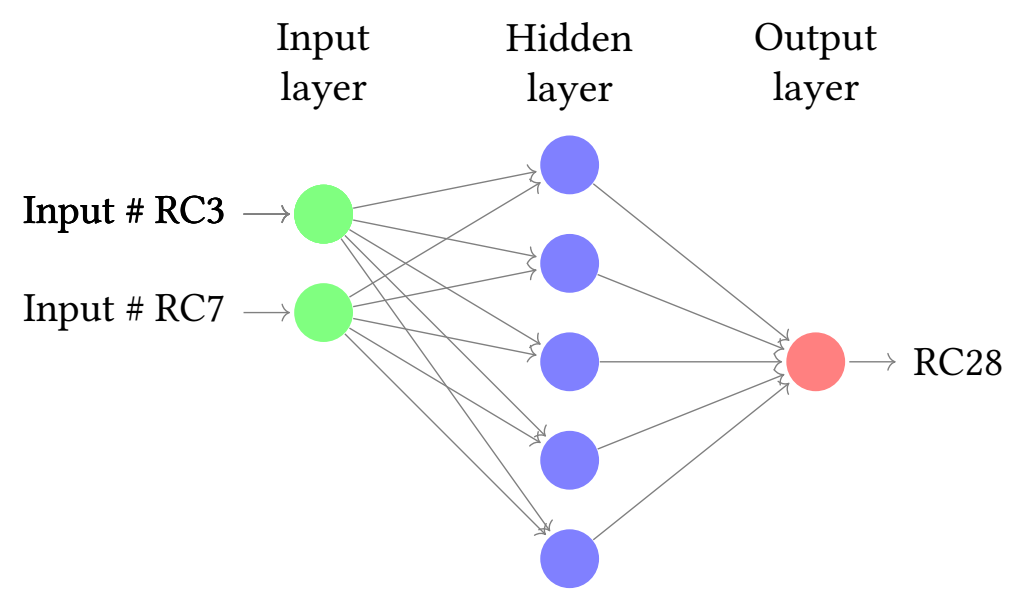

Figura 2.2: Um exemplo de Rede Neural no contexto dos dados de produção de cimento

\section{Uso para o problema de predição de RC}

Como os demais modelos, a predição será sempre o valor de RC28. As entradas serão as grandezas químicas correspondentes ao lote de cimento do qual gostaríamos de prever 
o RC28, ou seja, para o lote de cimento $i$ um vetor da forma $\left(A l 2 O 3_{i}, R C 1_{i}, R C 3_{i} \ldots\right)$ para a predição de $R C 28_{i}$.

\section{Regularização L2}

Em Goodfellow et al., 2016, os autores definem regularização como "qualquer modificação em um algoritmo de aprendizado que diminua o erro de generalização mas não o seu erro de treinamento". A ideia é de penalizar o modelo pela sua complexidade no objetivo de treinamento, fazendo assim com que o modelo tenha menos capacidade de aprender a modelar o ruído inerente aos dados de treinamento, i.e. a parte que não ajuda na tarefa de aprendizado.

A regularização L2 consiste em adicionar a norma quadrada de todos os parâmetros do modelo ao objetivo de otimização. Dessa maneira o algoritmo é levado a encontrar valores menores para os parâmetros, visto que a otimização é direcionada a achar o menor valor possível do objetivo.

\subsection{Modelos Sequenciais para predição de RC28}

Modelos sequenciais consomem sequências de dados e também podem ser usados pra criar predições sequenciais (GoodfEllow et al., 2016). A área de NLP viu muitos novos resultados com o uso esses tipos de modelos para geração e classificação de textos, que são dados com natureza inerentemente sequencial. Para o caso desse trabalho, séries temporais também podem aproveitar da capacidade desses modelos de lerem múltiplas entradas ao mesmo tempo. Modelos sequenciais são bastante comuns para processamento de texto e áudio e outras famílias de dados cuja natureza é eminentemente uma sucessão de eventos no tempo. Dados de processos industriais comumente se encaixam nessa categoria, inclusive produção de cimento, logo, passíveis de serem usados juntamente com esses modelos.

\subsubsection{Janela Móvel com Filtragem Exponencial para RC28}

A abordagem usada em Tsamatsoulis, 2015 consiste em calcular regressões lineares em uma janela móvel de dados, simulando limitações reais do chão de fábrica. O objetivo da regressão é estimar o índice RC28 de um determinado lote de cimento, do qual possuímos análises químicas e resultados de outros ensaios usados como variáveis. Com o uso das regressões lineares também obtemos desvios-padrões de todos os coeficientes calculados relacionados a essas variáveis. Essa abordagem irá utilizar a ordem temporal desses dados para modelagem e predições. Diferentes conjuntos de variáveis serão usados dependendo da sua disponibilidade considerando a ordem e dia que essas ficam disponíveis na operação normal da fábrica.

Para um dia $t$ possuímos $R C 28_{t}$ e $\mathbf{x}_{t}$, respectivamente o objetivo da regressão e o vetor de entradas. A Tabela 3.1 determina quais entradas estão presentes em 
$\mathbf{x}_{t}$ para cada modelo usado. Seja o dia $T$ onde começa a aplicação do modelo. Acaba de ficar pronto o ensaio de RC28 do lote expedido 29 dias no passado, i.e. $R C 28_{T-29}$. O dataset móvel está no intervalo [ $\left.T-29-t_{d}, T-29\right]$ i.e. os pares $\left\{\left(\mathbf{x}_{T-29-t_{d}}, R C 28_{T-29-t_{d}}\right),\left(\mathbf{x}_{T-28-t_{d}}, R C 28_{T-28-t_{d}}\right) \ldots\left(\mathbf{x}_{T-29}, R C 28_{T-29}\right)\right\}, \quad t_{d}$ um hiperparâmetro.

Usa-se esse dataset para calcular pesos de 3 regressões diferentes para a predição de RC28.

\begin{tabular}{llllllllllllll}
\hline reglin_1 & AGP & AL2O3 & SIO2 & MGO & IP & FP & SBL & PF & P2O5 & FE2O3 & RC1 & & \\
reglin_3 & AGP & AL2O3 & SIO2 & MGO & IP & FP & SBL & PF & P2O5 & FE2O3 & RC1 & RC3 & \\
reglin_7 & AGP & AL2O3 & SIO2 & MGO & IP & FP & SBL & PF & P2O5 & FE2O3 & RC1 & RC3 & RC7 \\
\hline
\end{tabular}

Tabela 2.1: O conjunto de variáveis usado para cada um dos modelos, de maneira análoga ao apresentado no trabalho TSAMATSOULIS, 2015

No dia $T$ acabaram de ficar prontos os ensaios RC1, RC3 e RC7 respectivamente dos lotes expedidos nos dias $T-2, T-4$ e $T-8$. Os modelos descritos na Tabela 4.2 e treinados com o dataset do período [ $\left.T-29-t_{d}, T-29\right]$ são aplicados para prever o RC28 de acordo com a disponibilidade dos ensaios nessas 3 datas. reglin_1 é aplicado em $T-1$ para prever $R C 28_{T-1}$, reglin_3 em $T-4$ para prever $R C 28_{T-4}$ e reglin_7 em $T-8$ para prever $R C 28_{T-8}$.

Continuamos aplicando os modelos por $t_{f}$ dias, no dia $T+1$, por exemplo, iremos aplicar reglin_1,reglin_3 e reglin_7 respectivamente nos dias $T-1, T-3$ e $T-7$ e gerar novas predições para RC28 nessas datas.

A Tabela 2.2 mostra para cada modelo os intervalos de datas usadas para treinamento e predição, usando $t_{d}$ e $t_{f}$ como parâmetros determinantes do tamanho do dataset móvel e do horizonte de predição, respectivamente.

$\begin{array}{lll}\text { Modelo } & \text { Intervalo de Treinamento } & \text { Intervalo de Predição } \\ \text { reglin_1 } & {\left[T-29-t_{d}, T-29\right]} & {\left[T-1, T-1+t_{f}\right]} \\ \text { reglin_3 } & {\left[T-29-t_{d}, T-29\right]} & {\left[T-4, T-4+t_{f}\right]} \\ \text { reglin_7 } & {\left[T-29-t_{d}, T-29\right]} & {\left[T-8, T-8+t_{f}\right]}\end{array}$

Tabela 2.2: Intervalos de tempo usados como dados de treinamento e predição dos modelos.

Após $t_{f}$ dias um novo dataset é escolhido para recalcular os parâmetros das regressões e repete-se o processo com $T^{\prime}=T+t_{f}$. A Figura ?? ilustra, para um dia $T$, quais dados serão usados para treino e validação do modelo. 


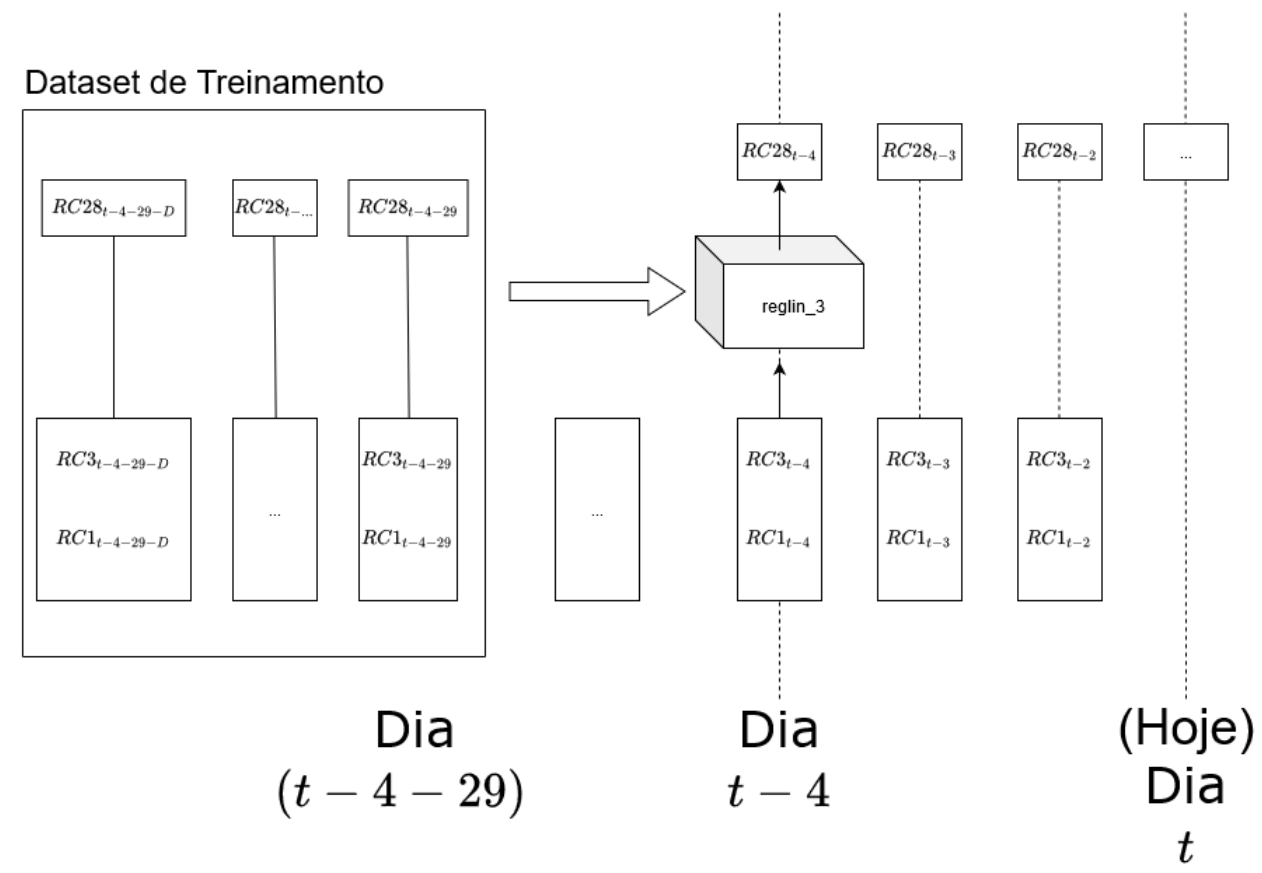

Figura 2.3: Diagrama representando o uso do modelo de regressão linear janelado na prática para os dados.

Para um tempo $t$, iremos designar as predições de cada um desses modelos, respectivamente, por $R \hat{C} 28_{t}^{\text {reglin_1 }}, R \hat{C} 28_{t}^{\text {reglin_3 }}$ e $R \hat{C} 28_{t}^{\text {reglin_}}{ }^{7}$.

Um quarto modelo é criado corrigindo as predições de reglin_1 com as de reglin_7, esse modelo será nomeado reglin_ew. Primeiramente calcula-se a diferença entre as predições de reglin_7 e as medidas reais de RC28 para o período $\left[T-29, T-29+t_{f}\right]$, visto que usamos os modelos por $t_{f}$ dias, novas anotações de RC28 se tornaram disponíveis nesse período.

$$
\operatorname{diff}_{i}=R \hat{C} 28_{i}^{\text {reglin_}}{ }^{\text {P }}-R C 28_{i}
$$

É aplicada então uma média móvel no vetor diff, com parâmetro $\alpha$, cujo resultado é o vetor filtrado diff_ew. O algoritmo da média móvel é mostrado na Equação 2.6:

$$
\begin{aligned}
& \text { diff_ew } w_{0}=\text { diff }_{0} \\
& \text { diff_ew } w_{t}=(1-\alpha) \text { diff } t_{t-1}+\alpha \text { diff }_{t}
\end{aligned}
$$

O valor das predições de reglin_1 são então corrigidos usando o vetor filtrado diff_ew. Os intervalos usados (emparelhados) são $t \in\left[T-1, T-1+t_{f}\right]$ para reglin_1 e $i \in$ $\left[T-29, T-29+t_{f}\right]$ para diff_ew. $k$ também é um hiper-parâmetro. 


$$
R \hat{C} 28_{t}^{\text {reglin_ew }}=R \hat{C} 28_{t}^{\text {reglin_1 }}+k * \text { diff_ew } w_{i}
$$

Levantando-se os erros quadráticos para os 4 modelos em seus períodos de teste, escolhem-se os hiper-parâmetros $t_{d}, k$ e $\alpha$. O parâmetro $t_{f}$ pode ser escolhido de acordo com a necessidade de controle de qualidade da fábrica. Nos testes realizados nesse trabalho, usamos $t_{f}=7$ para efeito de comparação com os modelos de Aprendizagem Profunda.

\subsubsection{Rede Neural Recorrente}

A família das Redes Neurais Recorrentes (RNN) é composta por modelos especializados em processar dados sequenciais (Goodfellow et al., 2016), da forma $x^{(1)}, x^{(2)}, x^{(3)} \ldots, x^{(T)}$. Uma rede neural recorrente é definida por uma função com recorrência ou recursão, de modo que no processamento de uma sequência o estado da rede seja de certo modo propagado temporalmente. A equação a seguir ilustra uma função com recorrência:

$$
h^{(t)}=f\left(h^{(t-1)}, x^{(t)} ; \theta\right)
$$

Nessa equação notamos que na iteração $t$ o valor do vetor $h$ depende de $h_{t-1}$. RNNs aprendem a usar esse vetores como "resumos" das iterações passadas. Desse modo , o modelo ganha a capacidade de usar informações passadas da sequência para o cálculo de uma saída. Essa capacidade porém começa a ser dificultada quando o modelo realiza muitas iterações temporais. Durante o aprendizado, sequências muito extensas criam problemas numéricos para o cálculo dos gradientes, esses podendo tomar valores muito pequenos ou muito grandes, esse fenômeno recebe o nome de gradientes desaparecidos. Foram propostos outros modelos que não possuam esse problema, como o modelo LSTM, explicado na sessão 2.5.3.

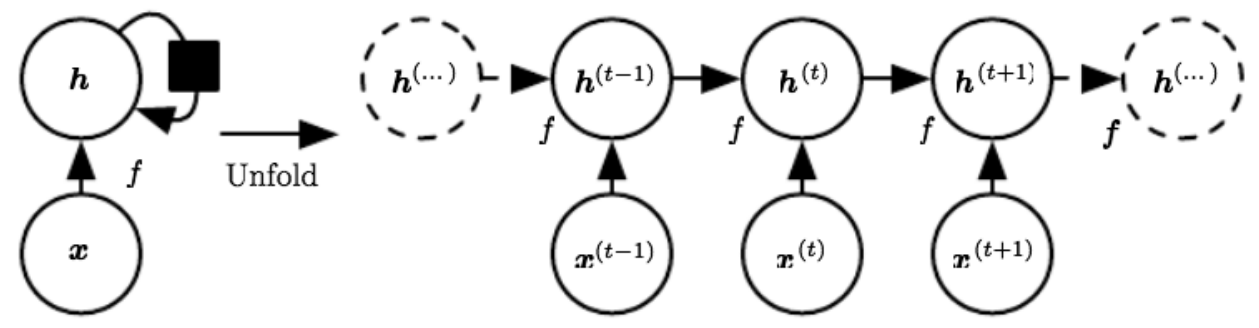

Figura 2.4: Grafo de Computação de uma RNN genérica (GOODFELLOW et al., 2016)

Como podemos ver na Figura 2.5, a entrada $x$, ao lado do estado interno $h$, são usados para calcular um novo estado. Nota-se que o vetor $h$, bem como os parâmetros internos da RNN, são divididos entre iterações temporais. 
Essa classe de modelos normalmente é usada para modelagem de linguagem. Buscando estimar uma distribuição de probabilidade $p\left(w_{t} \mid w_{t-1}, w_{t-2}, w_{t-3} \ldots\right)$ onde os $w_{i}$ são palavras subsequentes de um texto. Normalmente um modelo dessa natureza busca resolver um problema de classificação, onde a próxima palavra a ser prevista pelo modelo é uma entre todas as possibilidades de um certo vocabulário. No caso do domínio em questão desejamos resolver um problema de regressão, onde nosso alvo é um valor numérico. Para treinar um desses modelos, precisamos usar como entrada exemplos subsequentes de dados, onde cada exemplo de entrada tem um exemplo pareado de saída. Basicamente redes neurais recorrentes funcionam recebendo um exemplo de entrada, criando uma representação interna com o mesmo e então gerando uma saída e comparando essa saída com o exemplo de saída real, gerando um erro. Finalmente, esse erro é propagado para alterar seus parâmetros (com o fim de achar um conjunto de parâmetros que gere boas previsões).

Como já explicado anteriormente, nossos dados de entrada e saída não estão necessariamente pareados perfeitamente dia a dia. Portanto, foi necessário achar intervalos de tempo nos dados onde existe esse pareamento. Isso reduz drasticamente quais períodos representados nos dados realmente podem ser usados para treinar um desses modelos. 


\subsubsection{Consumo de dados de Cimento para Modelos baseados em RNNs}

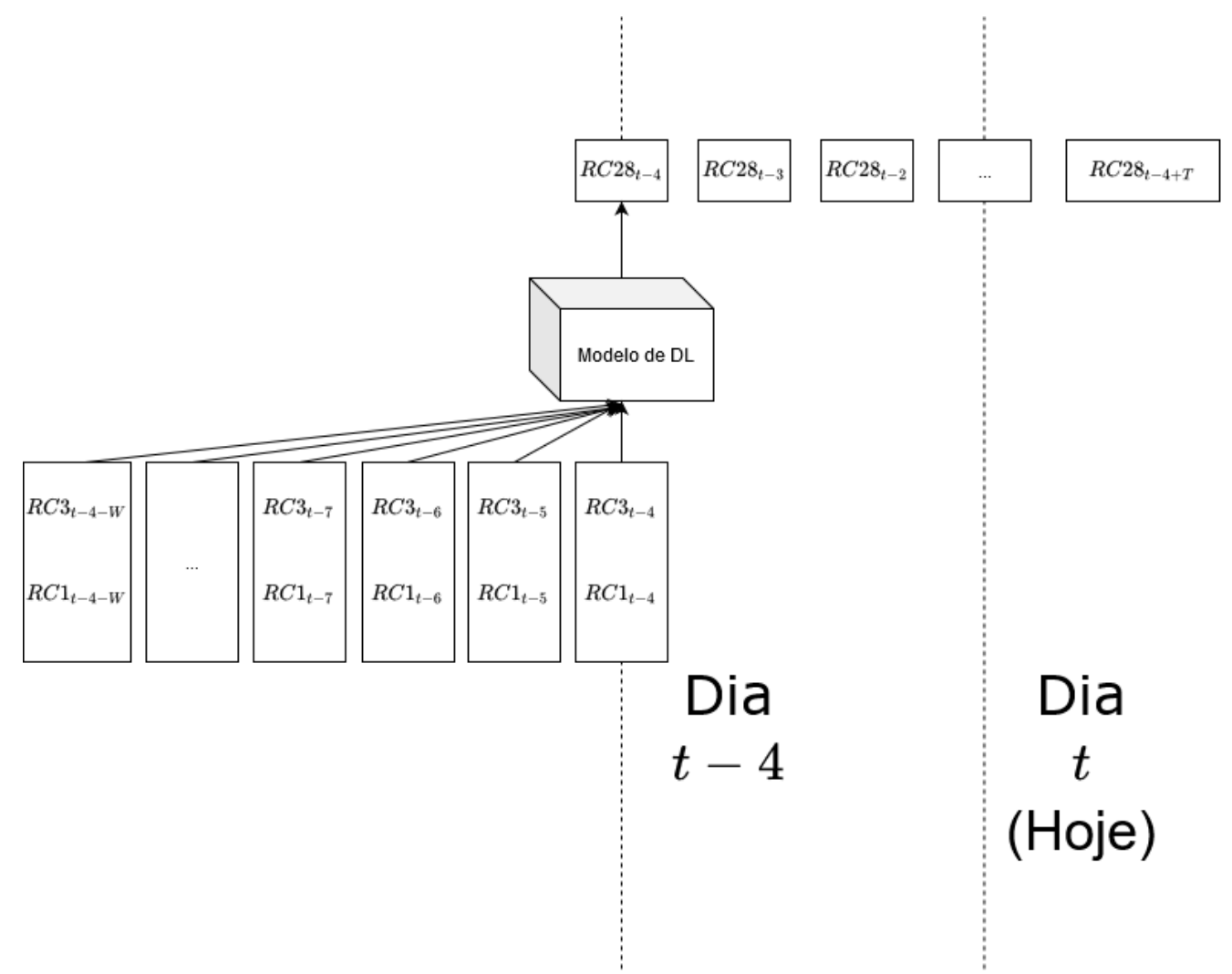

Figura 2.5: Diagrama com uma exemplificação do uso de modelos sequenciais baseados em RNNs para a predição de resistência $R C 28$.

\section{LSTM}

LSTMs (Hochreiter e SCHMidhuber, 1997) são um tipo de RNN que por meio de sua arquitetura permitem que sequências maiores sejam processadas sem que o fluxo dos gradientes propagados pela rede se torne numericamente problemático (i.e. tendendo a 0 ou a infinito). A Figura 2.6 ilustra o fluxo dos sinais em uma LSTM. Observa-se que a entrada $x_{t}$ e o antigo estado $h_{t-1}$ são usados para o cálculo de diversos gates ou "portas", e finalmente um novo estado $h_{t}$ é gerado.

Uma rede LSTM possui três "portas". Cada porta possui duas matrizes $W, U$ e um vetor $b$ de parâmetros. Uma iteração da LSTM começa com o cálculo dos sinais $o_{t}, i_{t}, f_{t}$.

$$
\begin{gathered}
f_{t}=\sigma_{g}\left(W_{f} x_{t}+U_{f} h_{t-1}+b_{f}\right) \\
i_{t}=\sigma_{g}\left(W_{i} x_{t}+U_{i} h_{t-1}+b_{i}\right) \\
o_{t}=\sigma_{g}\left(W_{o} x_{t}+U_{o} h_{t-1}+b_{o}\right)
\end{gathered}
$$


Figura 2.6: Diagrama da arquitetura de uma LSTM

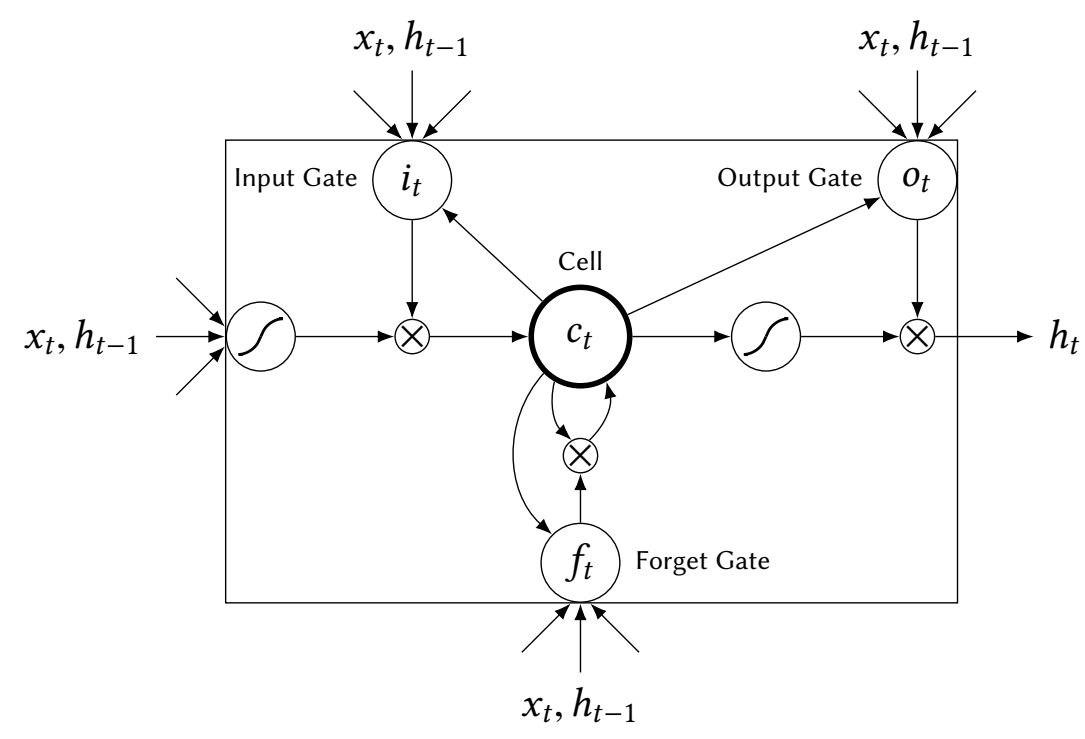

O diferencial de uma LSTM é a propagação do sinal $c_{t}$, a célula de memória. Esse valor depende de $f_{t}$ e $i_{t}$, que influenciam em como o valor da célula de memória será atualizado na presente iteração. A equação a seguir mostra como o valor da célula de memória é calculado. Onde o é o produto Hadamard, ou apenas multiplicação entrada por entrada de duas matrizes ou vetores.

$$
c_{t}=f_{t} \circ c_{t-1}+i_{t} \circ \sigma_{c}\left(W_{c} x_{t}+U_{c} h_{t-1}+b_{c}\right)
$$

Nota-se que $f_{t}$ define quanto do valor antigo da célula de memória deve participar no cálculo do seu novo valor. Da mesma maneira $i_{t}$ define quanto da nova entrada deve ser usada no cálculo desse valor. Em outras palavras, as portas $i_{t}$ e $f_{t}$ definem o quanto a LSTM deve, respectivamente, "lembrar" e "esquecer".

O novo estado da LSTM é então calculado por:

$$
h_{t}=o_{t} \circ \sigma_{h}\left(c_{t}\right)
$$

\section{Rede Encoder-Decoder}

Redes Encoder-Decoder são usadas para modelagem de sequência para sequência, ou seja, para receber dados sequenciais como entrada e gerar sequências como saída (GoodfEllow et al., 2016). Esses modelos possuem duas partes, ambas compostas por RNNs. 


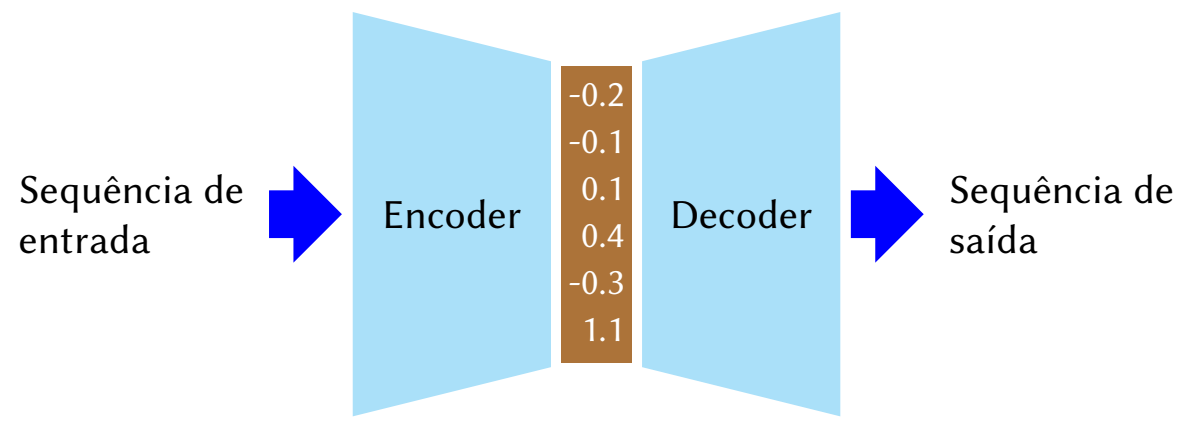

Figura 2.7: Diagrama de Rede Encoder-Decoder.

Modificado de (Neural Machine Translation - Tutorial ACL 2016 s.d.)

O encoder é uma RNN que busca receber uma sequência de entrada de tamanho arbitrário e gerar uma representação como saída, o seu estado interno, representando em marrom no diagrama acima. O Decoder então recebe essa representação interna (também chamada de codificação) e usa-a para gerar saídas sequencialmente, podendo então gerar essas sequências de duas formas: O Decoder pode usar as suas próprias saídas como entrada para gerar a saída da próxima iteração temporal, ou então usar dados de treinamento como entradas, essa última forma chamada de teacher forcing. No diagrama está indicado o acoplamento entre o decoder e o encoder. Essa codificação é apenas um vetor (cuja dimensão é um hiper-parâmetro de treinamento) que resume a informação sequencial lida pelo encoder e a transmite para o decoder. Hiper-parâmetros são parâmetros do problema de aprendizado que são definidos pelo programador e não fazem parte dos valores aprendidos pelo algoritmo de aprendizado. É comum que se realizem diversos experimentos com diferentes valores de hiper-parâmetros e se escolha os que geraram melhores resultados.

Redes encoder-decoder são muito usadas para aprender representações para os dados. Isso quer dizer que as codificações da rede encoder-decoder são frutos de transformações no espaço das entradas que buscam extrair a informação mais útil para o objetivo do aprendizado. Podemos pensar nessas transformações como mudanças de coordenadas nas quais estamos representando os dados. Justamente o problema de aprender representações estimulou desde 2006 uma redescoberta do DL (Goodfellow et al., 2016). Criar operações que transformem os dados de entrada de modo a facilitar o aprendizado pode levar anos se essa tarefa for colocada na mão de especialistas humanos (GoodfELlow et al., 2016), então é uma capacidade valiosa proporcionada por algoritmos de DL como redes encoder-decoder.

\section{Rede Neural Bayesiana}

Redes Neurais Bayesianas, como qualquer modelo bayesiano, especificam uma distribuição a priori da matriz $\theta$ de parâmetros. A Lei de Bayes é então aplicada para se calcular a distribuição posterior de $\theta$, em vez de uma estimativa pontual, como usualmente é feito no tratamento frequentista. Devido a complexidade desses modelos, é intratável calcular analiticamente essa distribuição posterior, então diversos métodos foram propostos para 
uma aproximação (Y. GAL, 2016). O método aplicado nesse trabalho é o Monte Carlo Dropout, que não requer nenhuma mudança na arquitetura do modelo para realizar a inferência. Consistindo apenas de uma reinterpretação de uma Rede Neural implementada com uma técnica de regularização chamada Dropout.

\section{Monte Carlo Dropout}

O processo de Inferência Variacional pode ser aproximado em uma rede neural pela técnica do Monte Carlo Dropout (Z. Gal Y., 2016).

O Monte Carlo Dropout consiste no uso de Dropout em todas as camadas da rede neural, i.e. descartar ativações aleatoriamente entre duas camadas da rede com probabilidade $p$.
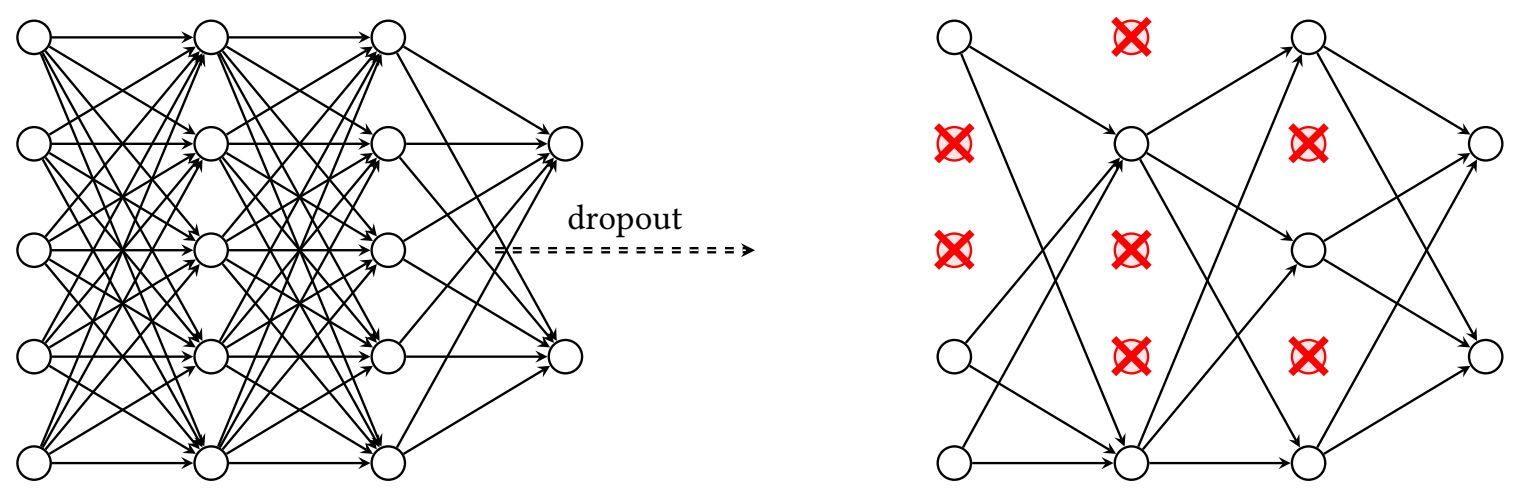

Figura 2.8: Representacão do uso de Dropout em uma rede neural

A cada computação da rede amostra-se com geradores de números aleatórios uma máscara que ira zerar valores de ativação entre camadas subsequentes. Iremos reparametrizar a rede neural com o fim de poder mostrar que o objetivo de otimização da rede com dropout é equivalente ao método de inferência variacional.

Seja uma rede neural, cuja matriz de parâmetros é $\theta$, com dimensões $K_{i}, K_{i-1}$, para cada camada $i$, e $L$ camadas. Define-se uma distribuição de probabilidade sob a matriz de parâmetros $q(\theta)$. Essa distribuição usa os pesos $M$ inicializados na rede e associa a eles a incerteza proveninente do método de Dropout. A distribuição $q(\theta)$ se comporta da seguinte maneira, onde $M_{i}$ e $p_{i}$, em cada camada, são considerados parâmetros variacionais:

$$
\begin{gathered}
\theta_{i}=M_{i} \operatorname{diag}\left(z_{i, j}\right) \quad \operatorname{para} j=1, \ldots K_{i} \\
z_{i, j} \sim \operatorname{Bernoulli}\left(p_{i}\right) \quad \text { para } i=1, \ldots L, j=1, \ldots K_{i-1}
\end{gathered}
$$

A função de custo de uma rede neural com dropout em todas as camadas e regularização L2 pode ser escrita da seguinte forma: 


$$
\mathcal{L}_{\text {dropout }}=\sum_{N=1}^{N}\left[y_{n}-f^{\theta^{*}}\left(x_{n}\right)\right]^{2}+\boldsymbol{\alpha}\left\{\theta^{2}\right\}
$$

O objetivo de minimização desse Rede Neural com dropout em todas as camadas é equivalente à diminuição da divergência KL entre $q(\theta)$ definido acima e a distribuição posterior $p(\theta \mid X, Y)$ de um Processo Gaussiano Profundo que parametriza a distribuição dos parâmetros da rede (Z. GAL Y., 2016). Seja $L$ o objetivo de inferência variacional da distribuição posterior do Processo Gaussiano Profundo, o trabalho (Z. GAL Y., 2016) mostra como podemos reescrever esse objetivo como a Equação 2.7:

$$
L=-\sum_{n=1}^{n} \int q(\theta) \log p\left(y_{n} \mid \theta, x_{n}\right) d \theta+K L(q(\theta), p(\theta))
$$

Cada termo do somatório é uma integral que será aproximada pelo método de Monte Carlo considerando-se apenas um termo, i.e. $\theta^{*} \sim q(\theta)$ :

$$
\begin{aligned}
& \sum_{N=1}^{N} \int q(\theta) \log p\left(y_{n} \mid x_{n}, \theta\right) d \theta \\
& \theta^{*} \sim q(\theta) \\
& \approx \sum_{N=1}^{N} \log p\left(y_{n} \mid x_{n}, \theta^{*}\right) \\
& =\sum_{N=1}^{N}\left[y_{n}-f^{\theta^{*}, b}\left(x_{n}\right)\right]^{2}
\end{aligned}
$$

A verossimilhança $\log p\left(y_{n} \mid \theta^{*}, x_{n}\right)$ é calculada pela função de custo $L\left[y_{n}, f^{\theta^{*}}\left(x_{n}\right)\right]$, no exemplo apenas a distância quadrada entre $y_{n}$ e a predição $f^{\theta^{*}}\left(x_{n}\right)$. da rede:

O segundo termo do objetivo de inferência é aproximado pela norma L2 dos parâmetros

$$
K L(q(\theta) \| p(\theta)) \approx \boldsymbol{\alpha}\left\{\theta^{2}\right\}
$$

Então, após realizado o treinamento, a saída do nosso modelo é uma amostragem da distribuição $q\left(y^{*} \mid x^{*}, X, Y\right)$. Se realizarmos $B$ computações de uma mesma predição e calcularmos a média e variância dessa amostra, esses serão estimadores não enviesados da média e variância de $p\left(y^{*} \mid x^{*}, X, Y\right)$, a distribuição das predições do modelo: 


$$
\begin{aligned}
& \widetilde{\mathbb{E}} {\left[y^{*}\right]=\frac{1}{B} \sum_{B=1}^{B} f^{\hat{W}, b}\left(x^{*}\right)=\frac{1}{B} \sum_{B=1}^{B} \hat{y}_{(B)}^{*} } \\
& \widetilde{\operatorname{Var}}\left[y^{*}\right]=\frac{1}{B} \sum_{B=1}^{B}\left(\hat{y}_{(B)}^{*}-\bar{y}^{*}\right)^{2}
\end{aligned}
$$

Esse método permite obter medida de incerteza a posteriori em modelos de rede neural frequentistas sem nenhuma alteração no método de otimização. Os resultados apresentados nessa sessão também valem para modelos de rede neural mais complexos como LSTMs (Z. GAL Y., 2016).

\section{Modelo Encoder-Decoder-Forecaster (Uber)}

Iremos utilizar nesse trabalho o modelo proposto em (LAPTEv et al., 2017). A arquitetura consiste em uma rede encoder-decoder que aprende codificações da série temporal (i.e. uma representação que resuma informações úteis para o problema) e uma rede forecaster que use essas codificações juntamente com variáveis exógenas a série temporal para realizar predições.

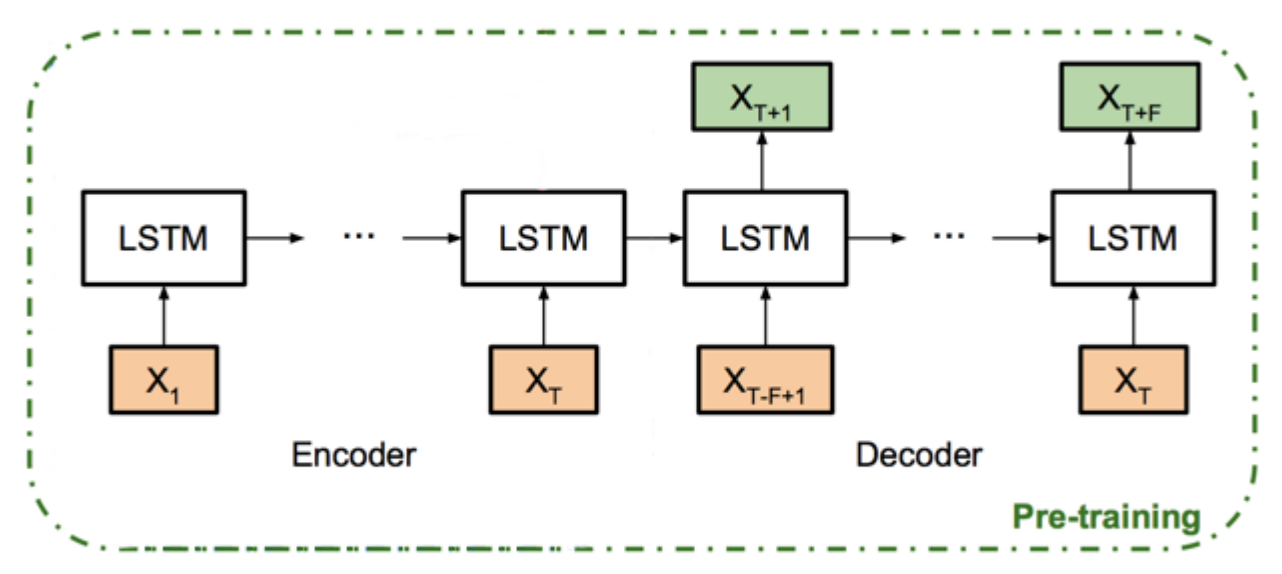

Figura 2.9: Modelo durante o Treinamento (LAPTEV et al., 2017)

Durante o pré-treinamento a rede encoder-decoder consome sequências de $F+T$ dias 
da série temporal. O encoder cria uma representação vetorial $h$ depois de receber como entrada os primeiros $T$ dias da sequência. Então, $h$ é usado como inicialização do estado interno do decoder, e esse então consume mais $F$ entradas da sequência. Para o decoder, se em uma iteração sua entrada é $X_{i}$, então sua saída será comparada com $X_{i+1}$, e esse erro é propagado após lidas todas as entradas para que a representação $h$ proveniente do encoder possa se tornar mais informativa.

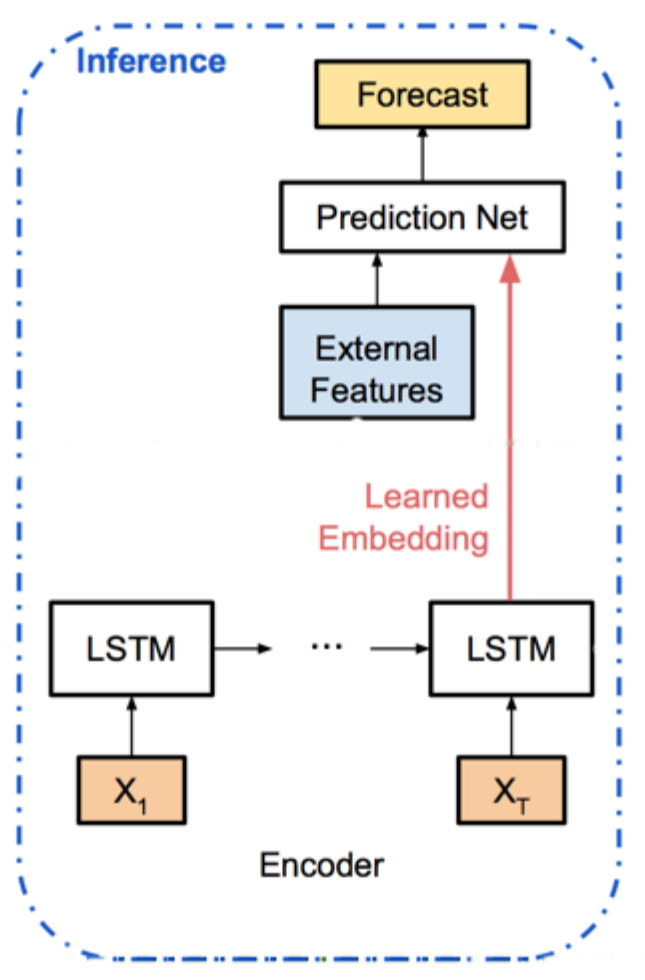

Figura 2.10: No módulo de inferência usamos uma rede neural simples para gerar predições a partir da codificação aprendida durante o pré-treino (LAPTEV et al., 2017)

Esse modelo também possui outra característica importante. Todas as camadas da redes neurais que compõe o encoder, o decoder e o forecaster possuem Dropout com probabilidade $p$. Ou seja, podemos usar a técnica do Monte Carlo Dropout para estimar a variância de cada predição feita por esse modelo. A rede então se torna um modelo bastante robusto para consumir séries temporais, assim realizando predições e incertezas.

Essa capacidade do modelo o torna mais interessante do que meramente usar uma rede LSTM para o problema de regressão. Agora iremos definir como a informação de incerteza pode ser calculada usando esse modelo.

Para esse problema usamos a verossimilhança $p\left(y \mid f^{\theta}(x)\right)$. Onde $f^{\theta}($.$) é a rede Encoder-$ Forecaster após o treino. Como estamos lidando com regressão, podemos especificar ainda essa verossimilhança como (LAPTEV et al., 2017): 


$$
p(y \mid \theta, x) \sim \mathcal{N}\left(f^{\theta}(x), \sigma^{2}\right)
$$

Desejamos encontrar a distribuição $p\left(y^{*} \mid x^{*}\right)$ para dados inéditos. Seguindo a formalização bayesiana, é necessário marginalizar os parâmetros do modelo da verossimilhança, i.e. resolver a Integral 2.2. Para esse modelo, como para muitos outros de interesse, essa integral é intratável. No trabalho (LAPTEV et al., 2017), os autores estudam a variância de $p\left(y^{*} \mid x^{*}\right)$ que quantifica a incerteza das predições. Primeiro essa variância é decomposta pela lei da variância total, e seus fatores são aproximados independentemente:

$$
\operatorname{Var}\left[y^{*} \mid x^{*}\right]=\operatorname{Var}\left[\mathbb{E}\left(y^{*} \mid \theta, x^{*}\right)\right]+\mathbb{E}\left[\operatorname{Var}\left(y^{*} \mid \theta, x^{*}\right)\right]
$$

$\mathbb{E}\left[y^{*} \mid \theta, x^{*}\right]$ é a verossimilhança do modelo, ou seja:

$$
\operatorname{Var}\left[\mathbb{E}\left(y^{*} \mid \theta, x^{*}\right)\right]=\operatorname{Var}\left[f^{\theta}\left(x^{*}\right)\right]
$$

$\operatorname{Var}\left[f^{\theta}\left(x^{*}\right)\right]$ representa a incerteza do modelo, e a estimativa desse valor será feito pela técnica do MC Dropout. A variância será aproximada pela variância amostral de $B$ predições estocásticas calculadas na rede com camadas de Dropout ativadas. Seja $\left\{\hat{y}_{(1)}^{*}=f^{\theta_{(1)}}\left(x^{*}\right), \hat{y}_{(2)}^{*}=f^{\theta_{(2)}}\left(x^{*}\right), \ldots \hat{y}_{(B)}^{*}=f^{\theta_{(B)}}\left(x^{*}\right)\right\}$ o vetor de predições amostrado dessa forma, e $\bar{y}^{*}$ sua média amostral, temos:

$$
\operatorname{Var}\left[f^{\theta}\left(x^{*}\right)\right] \sim \eta_{1}^{2}=\frac{1}{B} \sum_{B=1}^{B}\left(\hat{y}_{(B)}^{*}-\bar{y}^{*}\right)^{2}
$$

O termo $\mathbb{E}\left[\operatorname{Var}\left(y^{*} \mid \theta, x^{*}\right)\right]$ da Equação 2.10, o ruído inerente do modelo, será estimado com um conjunto de dados de validação. Sejam $\left(X^{\prime}, Y^{\prime}\right)$ dados de validação, com $V$ entradas. Esses dados são independentes do modelo treinado $f^{\theta}($.), então podemos usá-los para estimar o ruído inerente do modelo:

$$
\mathbb{E}\left[\operatorname{Var}\left(y^{*} \mid \theta, x^{*}\right)\right] \sim \eta_{2}^{2}=\frac{1}{V} \sum_{V=1}^{V}\left(y_{v}^{\prime}-f^{\theta}\left(x_{v}^{\prime}\right)\right)^{2}
$$

A Equação 2.10 fica resumida em:

$$
\operatorname{Var}\left[y^{*} \mid x^{*}\right] \sim \eta_{1}^{2}+\eta_{2}^{2}
$$

O desvio-padrão total do modelo é então calculado por:

$$
\eta=\sqrt{\eta_{1}^{2}+\eta_{2}^{2}}
$$




\section{Uso do modelo para predição de RC}

No caso de predição de RC28, o modelo será alimentado com diversas anotações temporais de lotes de cimento diferentes. Assim como ilustrado no Diagrama 2.5, o modelo irá absorver vetores da forma $\left(A L 2 O 3_{i}, R C 1_{i}, R C 3_{i} \ldots\right)$ para um certo intervalo de valores de $i$. Usaremos então o estado do modelo para prever $R C 28_{i}, \ldots R C 28_{i+F}$, onde $F$ será um parâmetro determinado por validação cruzada.

\subsubsection{Modelo DeepAR}

O modelo DeepAR, proposto em (Flunkert et al., 2017), é baseado em redes neurais recorrentes auto-regressivas. Essa família de modelos auto-regressivos, que é bastante usada em econometria, usa saídas passadas como entradas para o cálculo de próximos valores. Dessa maneira ,em tese, esses modelos podem gerar predições em horizontes de tempo arbitrários no futuro. Usa-se a função de verossimilhança binomial para que o modelo seja capaz de realizar predições probabilísticas.

O modelo é descrito pela seguinte equação, onde $h$ é uma RNN implementada com células de LSTMs:

$$
h_{i, t}=h\left(h_{i, t-1}, y_{i, t-1}^{*}, x_{i, t}, \theta\right)
$$

O modelo é treinado em um conjunto de diversas séries temporais $y_{i}$ do processo em estudo, todas representando o mesmo período de tempo. Nota-se que o estado da RNN tem como argumento o estado anterior e os parâmetros de entrada, mas também a saída da iteração passada do modelo, $y_{i, t-1}^{*}$.

A verossimilhança do modelo, $p\left(y_{i, t} \mid \mu, \sigma\right)$, é uma distribuição fixa cujos parâmetros $\mu, \sigma$ são dados por uma função determinística da saída $h$ do modelo. Usaremos uma função de verossimilhança binomial já que estamos otimizando um objetivo de regressão.

$$
p(y \mid \mu, \sigma)=\left(2 \pi \sigma^{2}\right)^{-\frac{1}{2}} \exp \left(-\frac{-y-\mu^{2}}{2 \sigma^{2}}\right)
$$

A média $\mu$ e o desvio-padrão $\sigma$ são calculados diretamente pela saída do modelo. Para a média, usamos uma transformação linear parametrizada por $W_{\mu}, b_{\mu}$. No caso do desvio-padrão, para garantirmos que ele seja maior que 0 , usamos uma função softplus após uma transformação linear análoga ao caso da média, parametrizada por $W_{\sigma}, b_{\sigma}$.

$$
\begin{aligned}
\mu\left(h_{i, t}\right) & =W_{\mu} h_{i, t}+b_{\mu} \\
\sigma\left(h_{i, t}\right) & =\log \left(1+\exp \left(W_{\sigma} h_{i, t}+b_{\sigma}\right)\right)
\end{aligned}
$$




\section{Treinamento}

O modelo possui uma etapa de treinamento e uma etapa de validação. O Diagrama 2.12 ilustra como o modelo se comporta em cada um desses momentos:

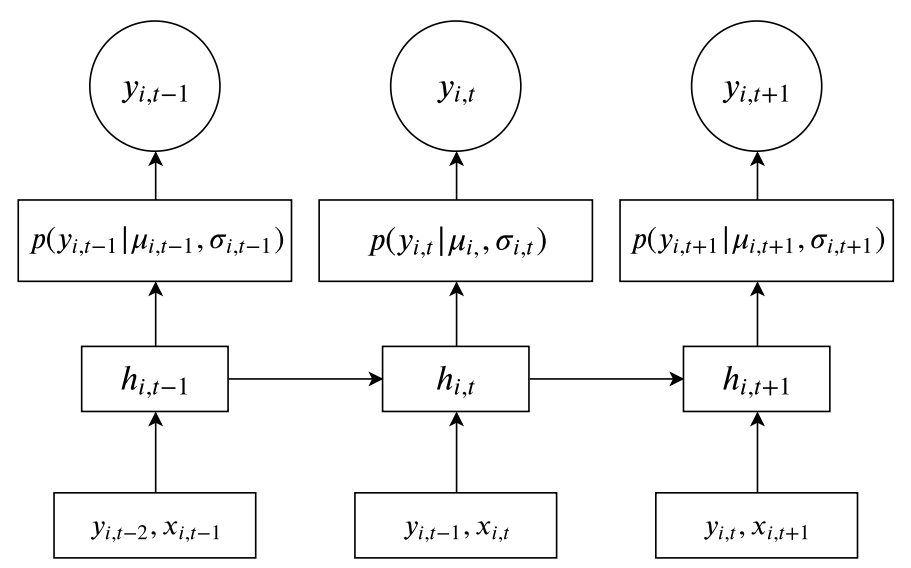

Figura 2.11: Para o treino, o modelo é guiado por anotações reais de valores passados da série alvo $y$ e as variáveis independentes $x$. Usamos o estado $h$ da rede LSTM a cada iteração temporal para calcular $\mu$ e $\sigma$. Esses valores são então usados no calculo da verossimilhança $p(y \mid \mu, \sigma)$, o valor que é minimizado.

O treinamento do modelo é feito pela maximização da log-verossimilhança:

$$
\mathcal{L}=\sum_{t=1}^{n} \log p\left(y_{i, t} \mid \mu_{i, t}, \sigma_{i, t}\right)
$$

Durante a etapa de predição, os valores calculados de $\mu$ e $\sigma$ são usados como parâmetros de uma distribuição normal que caracteriza a distribuição de cada predição $y^{*}$. 


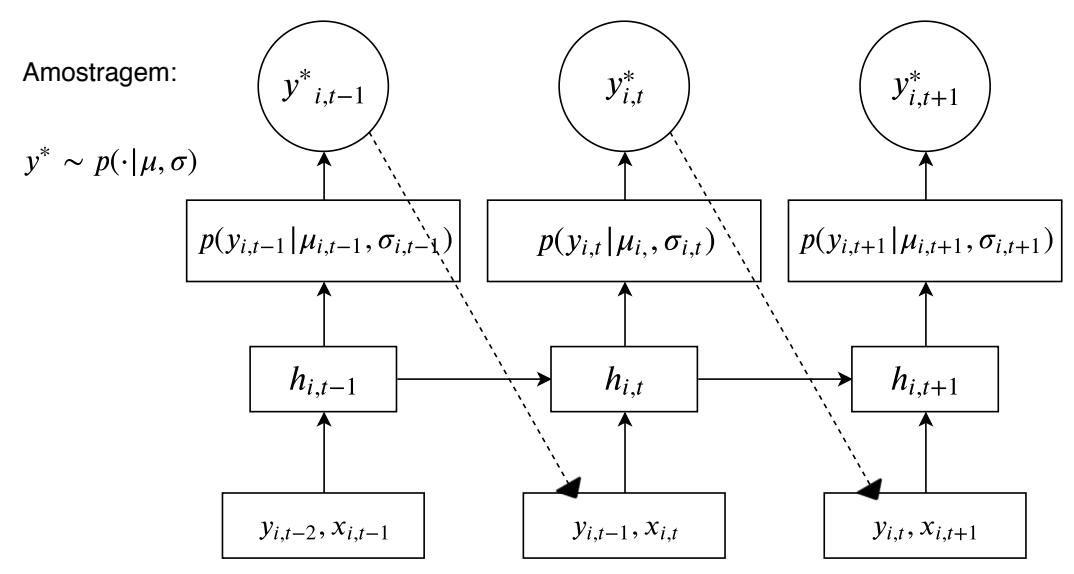

Figura 2.12: Se desejarmos prever mais de um valor da série-alvo y no futuro. O modelo é realimentado com os valores amostrados de $y^{*}$ e a rede continua a realizar predições.

Uma saída $y_{i, t}^{*}$ do modelo é calculada por meio de uma amostragem da Gaussiana determinada pela média e variância calculadas:

$$
y_{i, t}^{*} \sim \mathcal{N}\left(\mu_{i, t}, \sigma_{i, t}\right)
$$

\section{Uso do modelo para predição de RC}

No caso de predição de RC28, o modelo será alimentado com diversas anotações temporais de lotes de cimento diferentes. Assim como ilustrado no Diagrama 2.5, o modelo irá absorver vetores da forma $\left(A L 2 O 3_{i}, R C 1_{i}, R C 3_{i} \ldots\right)$ para um certo intervalo de valores de $i$. Usaremos então o estado do modelo para prever $R C 28_{i}, \ldots R C 28_{i+F}$, onde $F$ será um parâmetro determinado por validação cruzada.

\subsubsection{Modelo com Deep Factors}

O modelo Deep Factors with Gaussian Process (Maddix et al., 2018) separa o problema de predição em uma parte local, modelada por um Processo Gaussiano que gera incertezas, e uma parte fixa, modelada por uma rede neural recorrente treinada em diversas séries temporais do mesmo domínio. 
Um Processo Gaussiano é uma coleção de variáveis aleatórias, sendo que qualquer subconjunto finito das mesmas é distribuído normalmente (RASMUSSEN e WiLliams, 2005).

Um Processo Gaussiano é descrito completamente pela sua função de média e sua função de covariância. Usamos essas duas funções para amostrar o processo estocástico $f(x)$ que está sendo modelado:

$$
f(x) \sim \mathcal{G P}\left(m(x), K\left(x, x^{\prime}\right)\right)
$$

É comum que se escolha como função média apenas a constante 0 (RASMUSSEN e Williams, 2005). A função de covariância, as vezes chamada de Kernel, deve especificar a covariância entre os pares de variáveis aleatórias (i.e. os dados), para problemas de regressão é usual escolhermos um Kernel que relacione uma medida de distância das variáveis de entrada. Como por exemplo o quadrado da função exponencial:

$$
K\left(x, x^{\prime}\right)=\exp \left(-\frac{1}{2}\left|x-x^{\prime}\right|^{2}\right)
$$

\section{Modelo Generativo}

O modelo Deep Factors então é composto por duas partes, a combinação linear de ambas é a saída do modelo i.e. a emissão de valores de saída amostrados:

\section{Gerador da parte fixa aprendida globalmente: $f_{i, t}=W_{i} g_{t}\left(x_{i, t}\right)$}

A função $g_{t}$ é uma RNN, no caso desse trabalho uma célula LSTM, que recebe como entrada um certo número $T$ de passos da série temporal, e então emite como saída um horizonte finito $F$ de predições.

$$
\text { Gerador de ruído local: } r_{i} \sim \mathcal{G P}\left(0, K_{i}(., .)\right)
$$

O ruído é gerado por um Processo Gaussiano com média 0 e função de covariância exponencial. O Processo gera incertezas a partir da matriz de covariância calculada com todas as predições da parte global do modelo. Seja $f_{i}$ um vetor de predições com $T$ entradas calculado pela rede LSTM para a série temporal $i$, a matriz de covariância terá a forma:

$$
\left[\begin{array}{cccc}
1 & K\left(f_{i, 1}, f_{i, 2}\right) & \ldots & K\left(f_{i, 1}, f_{i, T}\right) \\
K\left(f_{i, 2}, f_{i, 1}\right) & 1 & \ldots & K\left(f_{i, 2}, f_{i, T}\right) \\
\vdots & \vdots & \ddots & \vdots \\
K\left(f_{i, T}, f_{i, 1}\right) & K\left(f_{i, T}, f_{i, 2}\right) & \ldots & 1
\end{array}\right]
$$


Emissão: $y_{i, t}^{*} \sim p\left(. \mid u_{i, t}\right), u_{i, t}=r_{i, t}+f_{i, t}$

A emissão ira combinar efeitos globais e ruído local para gerar as predições finais amostrando-se a variável latente $u$ :

\section{Treinamento}

Para o problema de regressão, podemos assumir que $p\left(. \mid u_{i, t}\right)$ é distribuida normalmente, então não precisamos de inferência para calcular a verossimilhança do modelo, que é dada por:

$$
p\left(y_{i}\right)=\mathcal{N}\left(f_{i}, K_{i}+\sigma_{i}^{2} \mathcal{I}\right)
$$

O objetivo de treinamento é achar o conjunto de parâmetros da RNN e do Processo Gaussiano que maximizem a log-verossimilhança dos dados:

$$
\mathcal{L}=\sum_{t=0}^{N} \log p\left(y_{t} \mid x_{t}\right)
$$

\section{Uso do modelo para predição de RC}

No caso de predição de RC28, o modelo será alimentado com diversas anotações temporais de lotes de cimento diferentes. Assim como ilustrado no Diagrama 2.5, o modelo irá absorver vetores da forma $\left(A L 2 O 3_{i}, R C 1_{i}, R C 3_{i} \ldots\right)$ para um certo intervalo de valores de $i$. Usaremos então o estado do modelo para prever $R C 28_{i}, \ldots R C 28_{i+F}$, onde $F$ será um parâmetro determinado por validação cruzada.

\subsection{Correlação entre Variáveis}

Sejam duas amostras de variáveis aleatórias $X, Y$ pareadas $\left[x_{1}, x_{2}, \ldots, x_{n}\right] \mathrm{e}$ $\left[y_{1}, y_{2}, \ldots, y_{n}\right]$, calcula-se o índice de correlação de Pearson por:

$$
r=\frac{\sum_{i=1}^{n}\left(x_{i}-\bar{x}\right)\left(y_{i}-\bar{y}\right)}{\sqrt{\sum_{i=1}^{n}\left(x_{i}-\bar{x}\right)^{2}\left(y_{i}-\bar{y}\right)^{2}}}
$$

O valor de $r$ está no intervalo [ $-1,1]$, onde 1 indica uma correlação positiva total, -1 uma correlação negativa (i.e. uma variável tem um efeito negativo na outra) e 0 a falta de correlação. 


\subsection{Normalização Min-Max}

Como os dados possuem variáveis com diferentes ordens de grandeza, convém normalizar essas variáveis para corrigir problemas de viés em certos modelos de ML. O método min-max deixa todas as entradas de uma variável entre 0 e 1 .

Seja um vetor $X=\left[x_{1}, x_{2}, \ldots, x_{n}\right]$. Podemos normaliza-lo por esse método usando a seguinte transformação:

$$
x_{i}^{*}=\left(x_{i}-\operatorname{Min}(X)\right) /(\operatorname{Max}(X)-\operatorname{Min}(X))
$$

$\operatorname{Min}(X)$ e $\operatorname{Max}(X)$ são constantes que devem ser guardadas para posterior desnormalização do vetor. Esse método de normalização será usado para preparar os dados para todos os modelos usados nesse trabalho. 



\section{Capítulo 3}

\section{Estudo dos Dados}

\subsection{Preparo dos Dados}

Os dados são anotados diariamente em planilhas para o controle da fábrica de Cajati. Estes estão distribuídos em colunas com diversas propriedades analisadas em laboratório de cada lote retirado da fábrica. Existem diversas planilhas para lotes retirados de diversas partes do processo de fabricação. Devido a dificuldades logísticas de se casar um mesmo lote de cimento em diferentes partes do processo (e.g. o mesmo lote ao sair do forno e depois de finalizado e pronto para expedição), estudos serão feitos apenas para os dados de expedição de cimento.

A Tabela 3.1 apresenta todas as variáveis, dependentes e independentes, que serão usadas na modelagem.

\begin{tabular}{|c|c|c|c|c|c|c|}
\hline Variáveis (unidade) & & & & & & \\
\hline Composição Química (\%) & $A L_{2} 0_{3}$ & $\mathrm{SIO}_{2}$ & MGO & RICARB & $\mathrm{P}_{2} \mathrm{O}_{5}$ & $\mathrm{~F}_{2} \mathrm{O}_{3}$ \\
\hline Água (\%) & AGP & & & & & \\
\hline Tempo até o começo e fim do endurecimento do material (s) & IP & FP & & & & \\
\hline Finura Blaine $\left(\mathrm{cm}^{2} / \mathrm{g}\right)$ & SBL & & & & & \\
\hline Resistência Compressiva do Cimento (kPA) & $\mathrm{RC} 3$ & $\mathrm{RC} 7$ & $\mathrm{RC} 28$ & & & \\
\hline
\end{tabular}

Tabela 3.1: Variáveis presentes nos dados de expedição de cimento cedidos pela Intercement

Os dados de expedição de cimento são anotados aproximadamente por dia, possuindo 2520 entradas para 3650 dias distintos. Existem dias sem dados presentes. O período contemplado pela planilha de dados vai do dia $02 / 01 / 2008$ até o dia 29/12/2018.

\subsubsection{Dados faltantes}

Embora tenhamos uma quantidade razoável de dias com dados presentes, esses muitas vezes não possuem algum valor de alguma variável. A seguir vemos para os dados de Expedição de Cimento, para cada uma de suas variáveis de entrada, a porcentagem de dados presentes. 


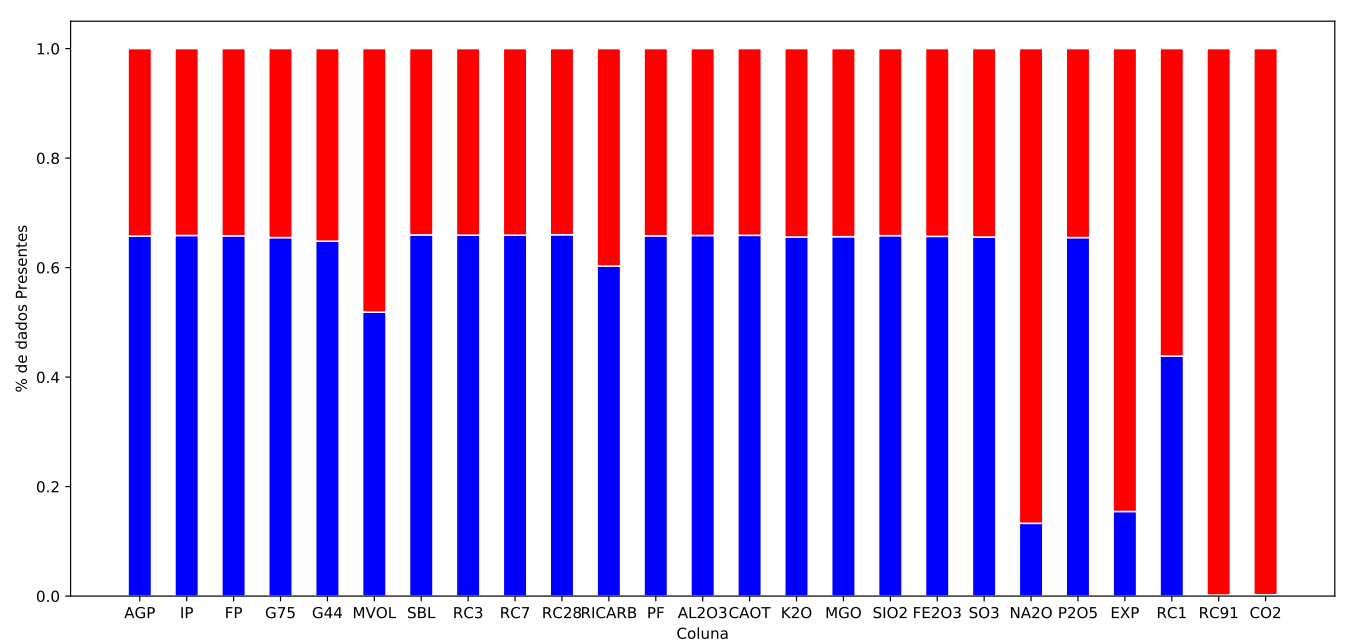

Figura 3.1: Porcentagem de dados faltantes por variável para dados de Expedição de Cimento. Cada coluna azul indica a porcentagem do total de dias contemplados pela planilha que contém dados dessa variável.

\subsection{Reamostragem dos dados}

Uma dos requisitos dos dados assumidos pelos modelos de séries temporais, que os mesmos são espaçados regularmente pelo incremento de tempo escolhido, sem lacunas. Portanto, os dados foram modificados para que entradas anotadas no mesmo dia sejam unificadas em um único dia. Além disso, para dias no intervalo de tempo estudado que não possuam entradas, foram criadas entradas com valores artificiais que não perturbem a distribuição dos dados, e.g. os valores da última entrada válida são copiados para frente até que se possua um novo valor.

A Figura 3.2 mostra como os dados estavam antes da reamostragem para que eles se tornem diários:

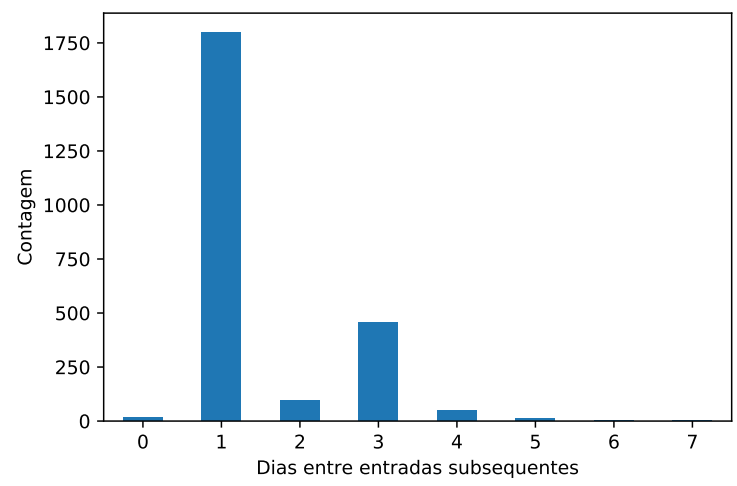

Figura 3.2: Distribuição das distâncias entre entradas subsequentes dos dados de Expedição de Cimento, antes da reamostragem. Grande parte das entradas da planilha estão distantes de 1 dia. Porém uma quantidade significativa tem 3 dias de intervalo (sem dados no meio). Para o trabalho será necessário preencher esses dias faltantes. 


\subsubsection{RC1, RC3, RC7 e RC28}

A variável de interesse para todos os modelos de predição é o RC28, o valor escolhido por normas de segurança de construção civil. Os modelos usados nesse trabalho irão buscar usar outros resultados de ensaios mais rápidos de resistência compressiva na predição do ensaio mais importante e demorado. É válido então uma análise de correlação entre essas grandezas.

A Figura 3.3 mostra um correlograma entre os índices RC1, RC3 e RC7 atrasados e o RC28 diário.
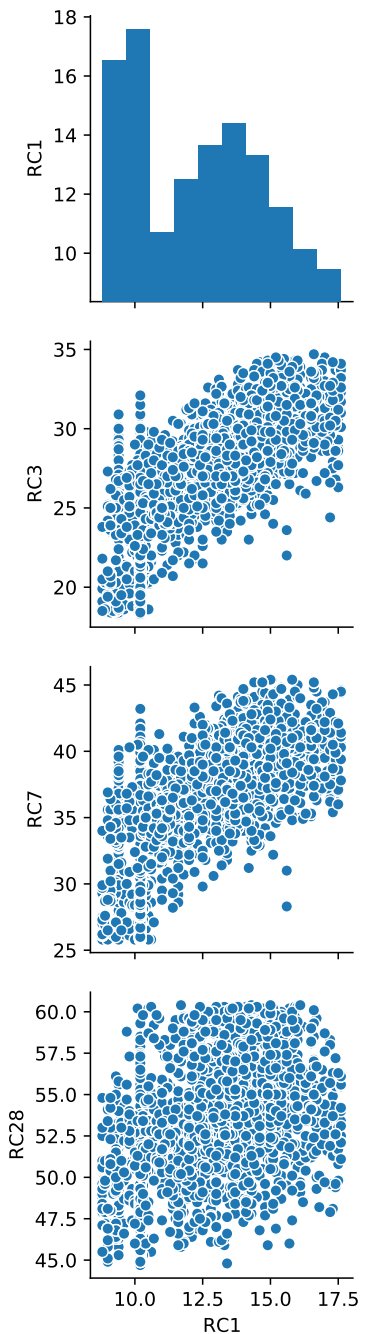
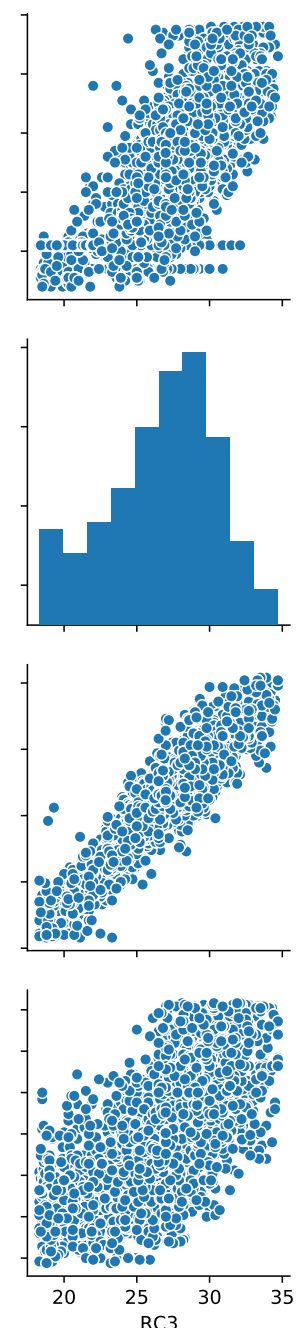
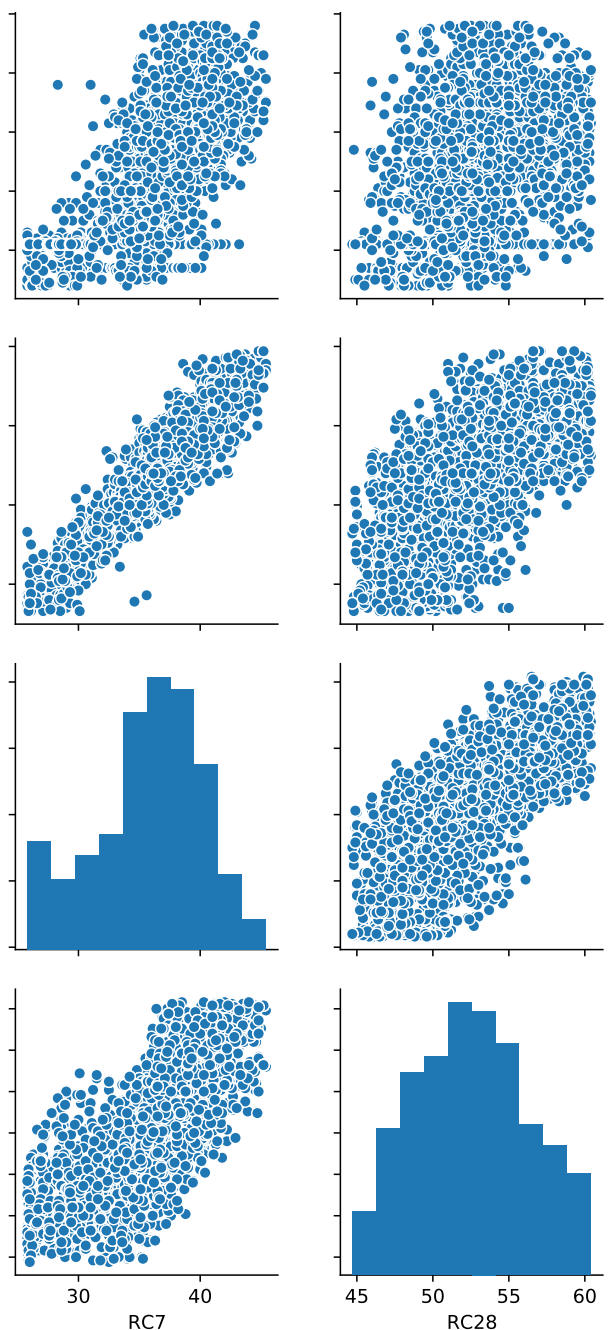

Figura 3.3: Correlograma dos índices de resistência compressiva. A diagonal mostra a distribuição de cada variável. Como esperado, RC28 tem uma correlação maior com ensaios mais recentes (i.e. $R C 7)$ do que com $R C 1$.

A Tabela 3.2 mostra o restante das correlações de Pearson (Goodfellow et al., 2016) entre as demais colunas de dados e o nosso objetivo, o índice RC28: 


\begin{tabular}{lr}
\hline & RC28 \\
\hline AGP & 0.592847 \\
AL2O3 & 0.463414 \\
P2O5 & 0.292252 \\
SIO2 & -0.053178 \\
MGO & -0.371414 \\
IP & -0.132297 \\
FP & -0.419800 \\
SBL & 0.396555 \\
PF & -0.480720 \\
\hline
\end{tabular}

Tabela 3.2: Tabela mostrando as correlações de Pearson entre cada uma das variáveis e o alvo $R C 28$.

É notável que o RC28 não possui uma alta correlação com nenhuma das propriedades do cimento. Tendo essa correlação apenas com os outros índices de resistência compressiva. 


\section{Capítulo 4}

\section{Resultados Experimentais}

\subsection{Modelos de Aprendizado de Máquina}

\subsection{Metodologia}

Em um primeiro momento, o problema é tratado como de Aprendizado Automático para dados não temporais. Para esses modelos como Redes Neurais, Árvores de Decisão e Regressões Lineares (Método dos Mínimos Quadrados) (Goodfellow et al., 2016), separamos os dados em treino e validação, normalizamos as variáveis e treinamos os modelos.

\subsubsection{Divisão dos dados entre treino e validação}

A divisão entre dados de treino e validação é feita da maneira padrão com modelos de Aprendizado de Máquina, separando-se $80 \%$ dos dados para treino e $20 \%$ para validação, i.e. testar o poder de generalização dos modelos (GoodfELLow et al., 2016). 


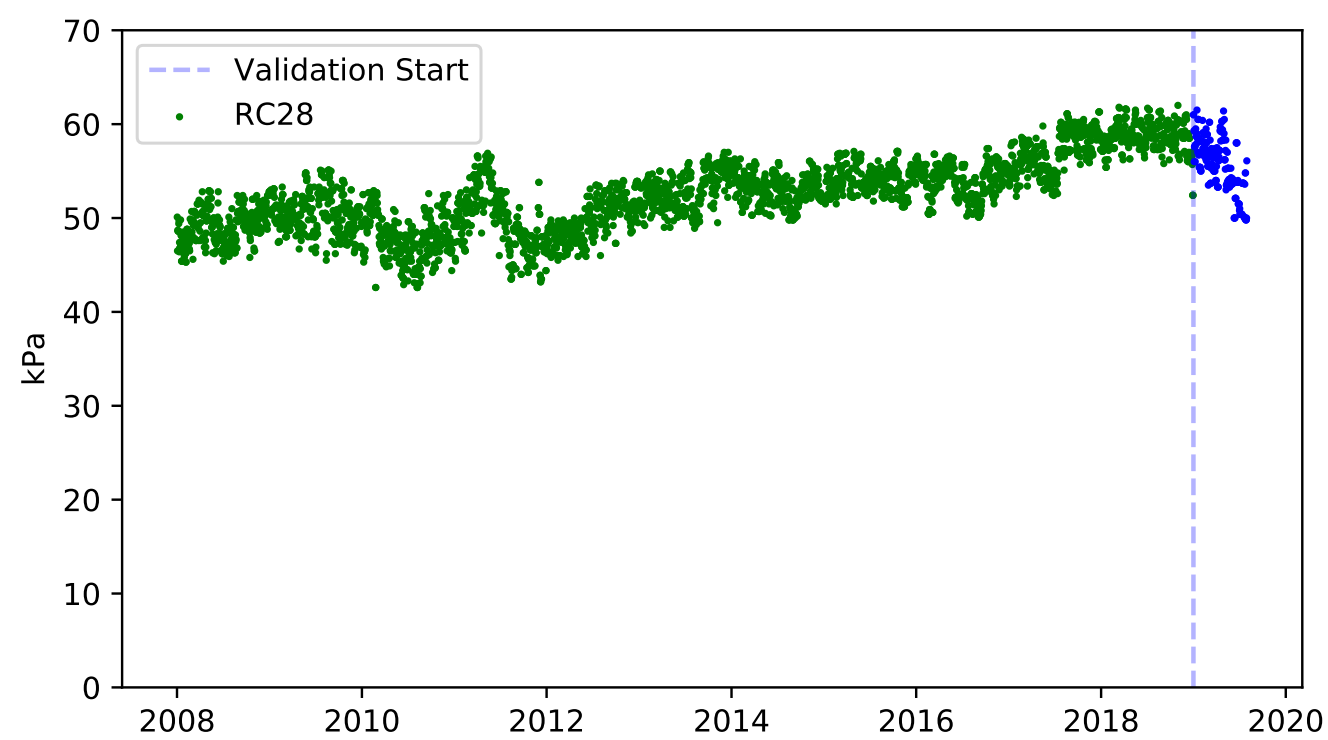

Figura 4.1: Divisão do dataset para a saída RC28, os pontos verdes foram usados para treino e os pontos azuis usados para validação.

Foram usadas implementações dos modelos fornecidos pela biblioteca Sklearn. As avaliações de RMSE de todo o conjunto de validação estão apresentados por modelos na Imagem 4.2. Vale ressaltar que não existe nenhuma característica temporal absorvida pelos modelos nesse experimento. Cada ponto de validação é calculado usando-se unicamente valores daquele lote particular, e nada de nenhum outro anterior temporalmente. 

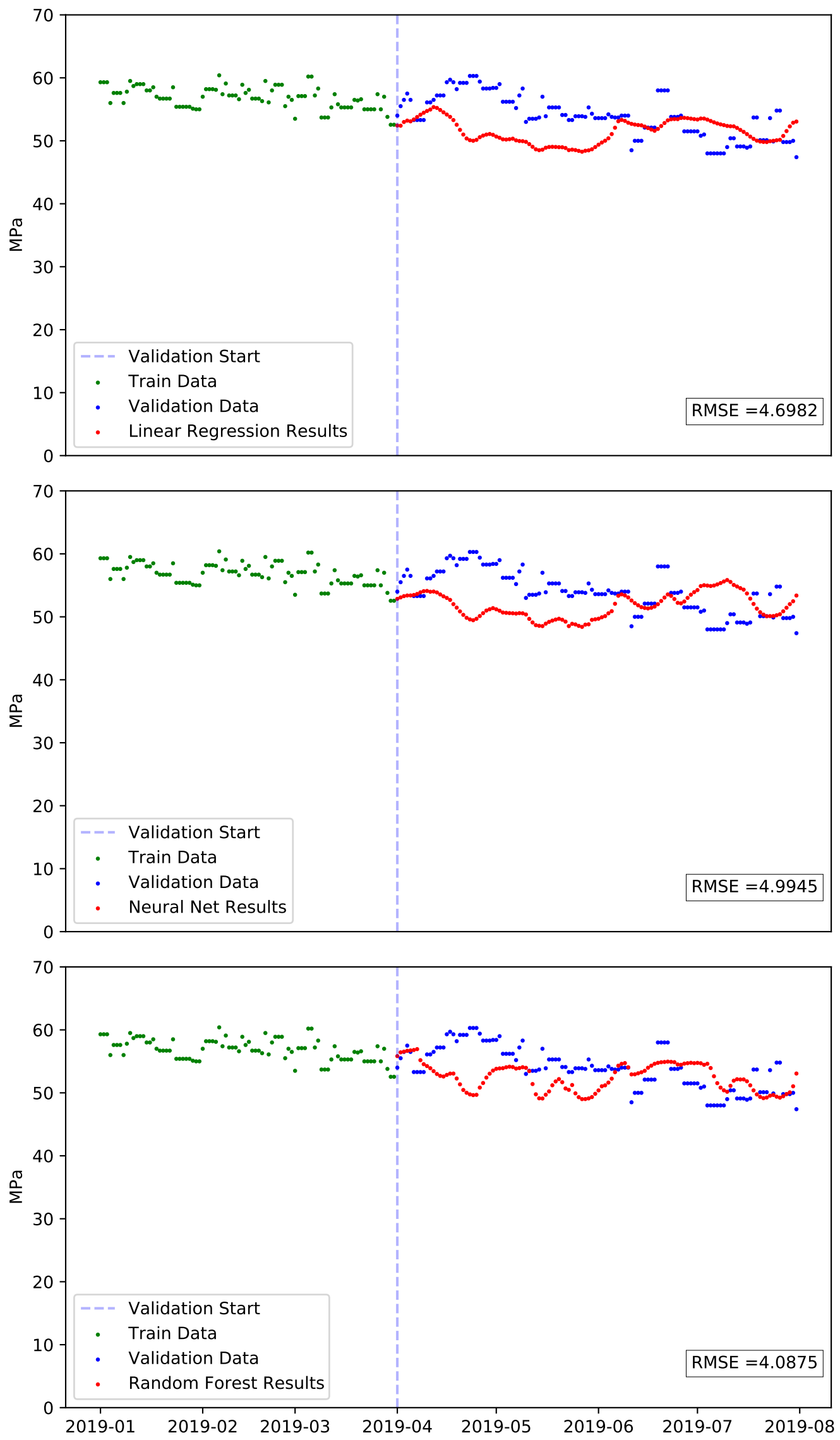

Figura 4.2: Predições nos dados de validação nos experimentos com modelos não-temporais. 
Na Tabela 4.1 reportamos os erros para predições imediatamente após o fim do último dia de dados usados para treino. A Tabela reporta o erro agregado para todo o dataset de testes.

Tabela 4.1: RMSE por modelo.

\begin{tabular}{|l|l|}
\hline Modelo & RMSE \\
\hline Regressão Linear & 4.69 \\
\hline Rede Neural & 4.99 \\
\hline Random Forest & 4.08 \\
\hline
\end{tabular}

Reportamos distribuição dos valores previstos, até 1 mês após a data onde começam os dados de validação (i.e. os dados não usados para treinamento), a Figura 4.3 mostra as distribuições previstas pelos 3 modelos:
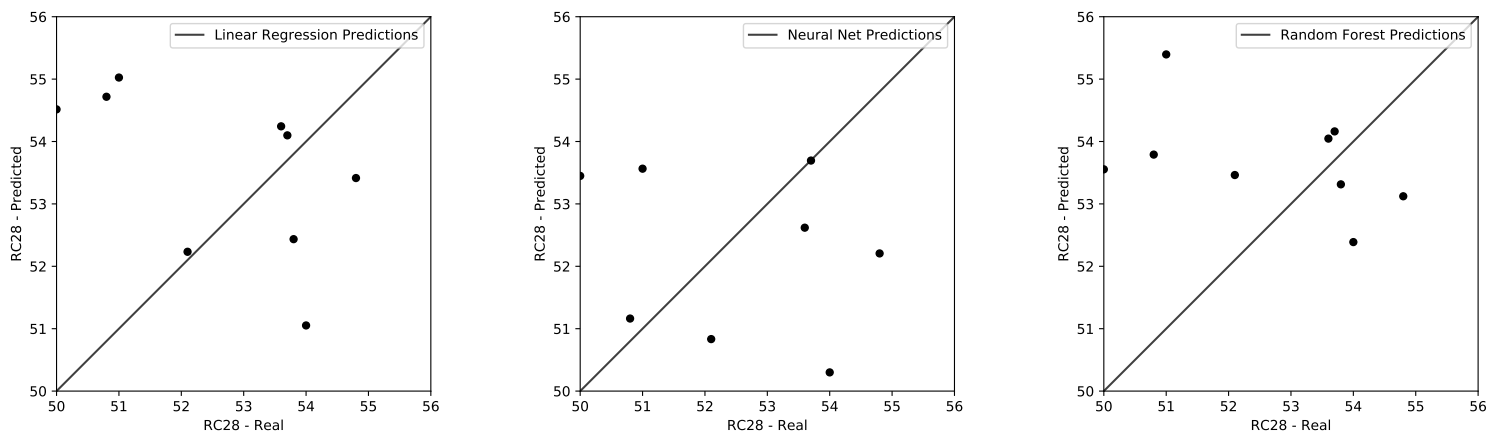

Figura 4.3: Valores reais plotados contra os valores previstos para análise da distribuição aprendida por cada modelo. Os modelos de Aprendizado de Máquina possuem flutuações altas na distribuição das predições, frutos de viés.

\subsection{Modelos de Séries Temporais}

\subsection{Metodologia}

Agora com um tratamento completo do problema como o de Aprendizado Automático para predição de séries temporais, consideramos os dados sequencialmente, treinando e testando o modelo a partir de janelas de $w$ entradas consumidas em sequência pelo o modelo. A tarefa destes é então gerar predições que continuem essa janela de dados. Como mencionado na introdução desse trabalho, um benefício das técnicas de Aprendizado Profundo é a de escalar tarefas de aprendizado para datasets de tamanho muito maior que era possível com modelos clássicos (Goodfellow et al., 2016). Para tarefas de regressão de séries temporais, modelos recentes utilizam diversas séries temporais de um mesmo processo simultaneamente. Os modelos poderão então ter parâmetros tanto locais (calculados para cada série) como globais (dividimos por todas as séries de treinamento). 
Para comparação, todos os modelos usamos uma janela de 15 dias de consumo de dados antes da realização de predições. Em todos os modelos, usamos batches de 64 janelas, com o otimizador Adam e taxa de aprendizagem de $1 e-4$ para o treino das LSTMs de cada modelo. Para o modelo Deep Factors usamos a taxa de $1 e-2$ para a busca de parâmetros do Processo Gaussiano. A lista completa de hiper-parâmetros usados para cada modelo de Aprendizado Profundo pode ser encontrada no Apêndice .1.

\subsubsection{Divisão dos dados entre treino e validação}

Com o fim de explorar essa capacidade dos modelos de consumirem diversas séries temporais, os dados da fábrica de Cajati foram separados por ano e consideramos cada ano como um exemplo do processo a ser modelado, fornecendo-os separadamente aos modelos. Os modelos de Aprendizado Profundo irão então usar parâmetros locais para cada ano de produção de cimento, mas globalmente buscar padrões para o funcionamento da fábrica. Para cada ano de 2012 até 2019 usaremos os primeiros 11 meses como dados de treinamento e os últimos 30 dias como dados de validação. Para os modelos temporais foi necessário descartar os anos de 2008 até 2012, visto que esses não possuiam anotações de RC1, que são necessárias para a análise temporal, por motivos que são explicados na Sessão 2.5.1. 

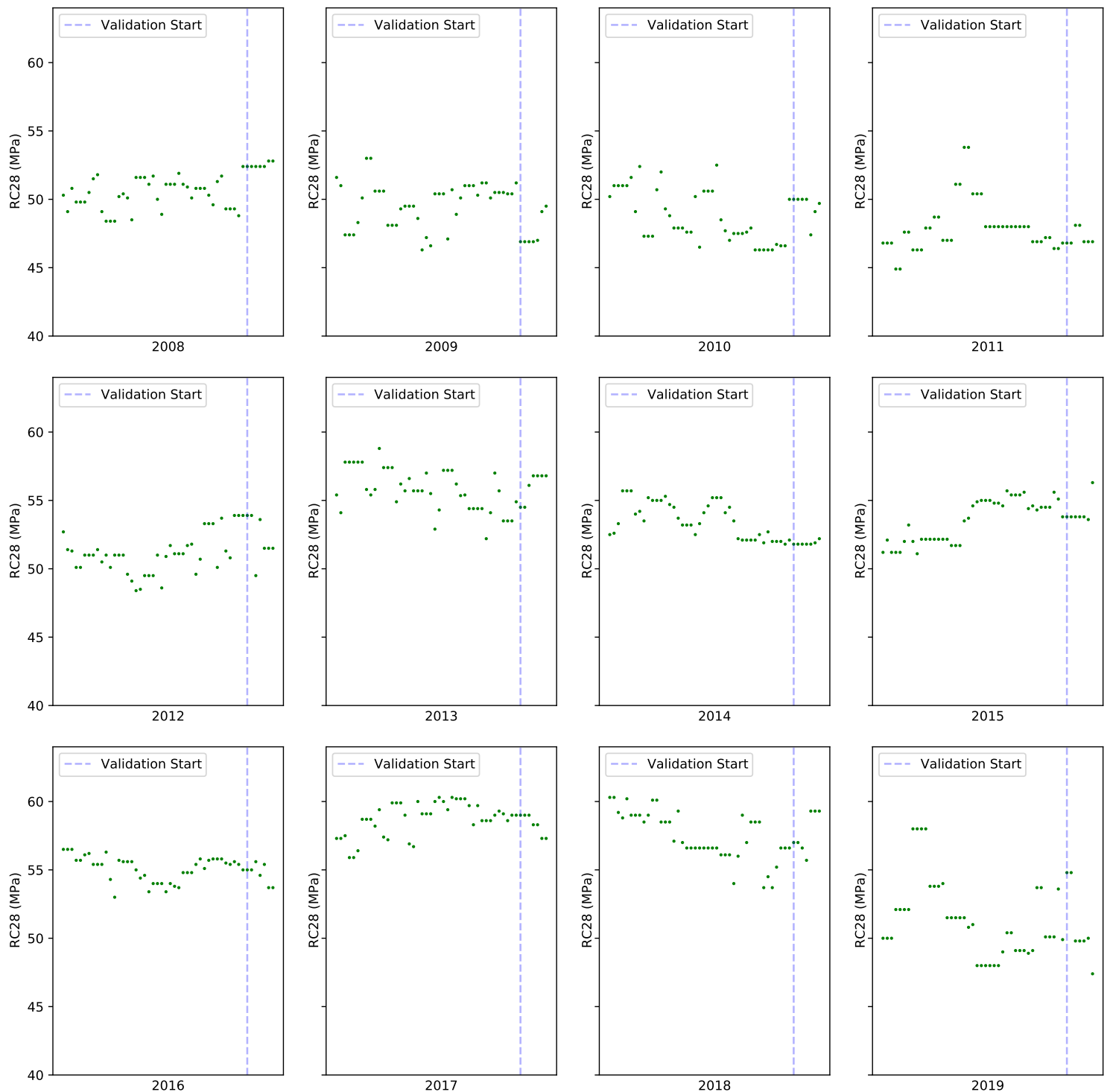

Figura 4.4: Os dados são divididos em 11 datasets separados, onde temos por dataset 11 meses usados para treino e os últimos dias do ano para validação.

\subsubsection{Regressão Linear Dinâmica com Filtragem Exponencial}

Com o fim de termos uma base de comparação para os modelos de Aprendizado Profundo, aplicaremos o modelo proposto em (Tsamatsoulis, 2015). Usaremos 3 modelos com diferentes grupos de variáveis, a Tabela 4.2, já referenciada na Sessão 2.5.1 mostra as variáveis presentes em cada modelo, e o nome dado aos modelos pelo restante desse trabalho. Também mostraremos resultados para o modelo corrigido reglin_ew, que é uma combinação dos modelos reglin_1 e reglin_7.

Os modelos foram testados com o parâmetro $t_{f}=7$ (i.e. simulamos o uso do modelo por 7 dias) com o índice $T$ referente ao começo das predições sendo o primeiro dia de dezembro para cada dataset. Os resultados para cada modelo no período de validação de cada ano são reportados nas Figuras 4.5,4.6 e 4.7. Os modelos DeepAR de modo geral 


\begin{tabular}{llllllllllllll}
\hline reglin_1 & AGP & AL2O3 & SIO2 & MGO & IP & FP & SBL & PF & P2O5 & FE2O3 & RC1 & & \\
reglin_3 & AGP & AL2O3 & SIO2 & MGO & IP & FP & SBL & PF & P2O5 & FE2O3 & RC1 & RC3 & \\
reglin_7 & AGP & AL2O3 & SIO2 & MGO & IP & FP & SBL & PF & P2O5 & FE2O3 & RC1 & RC3 & RC7 \\
\hline
\end{tabular}

Tabela 4.2: $O$ conjunto de variáveis usado para cada um dos modelos, de maneira análoga ao apresentado no trabalho TSAMATSOULIS, 2015

seguem a tendência dos valores corretos de RC28, que são naturalmente ruidosos, como pode ser percebido pelas curvas azul claro mostrando os valore reais.
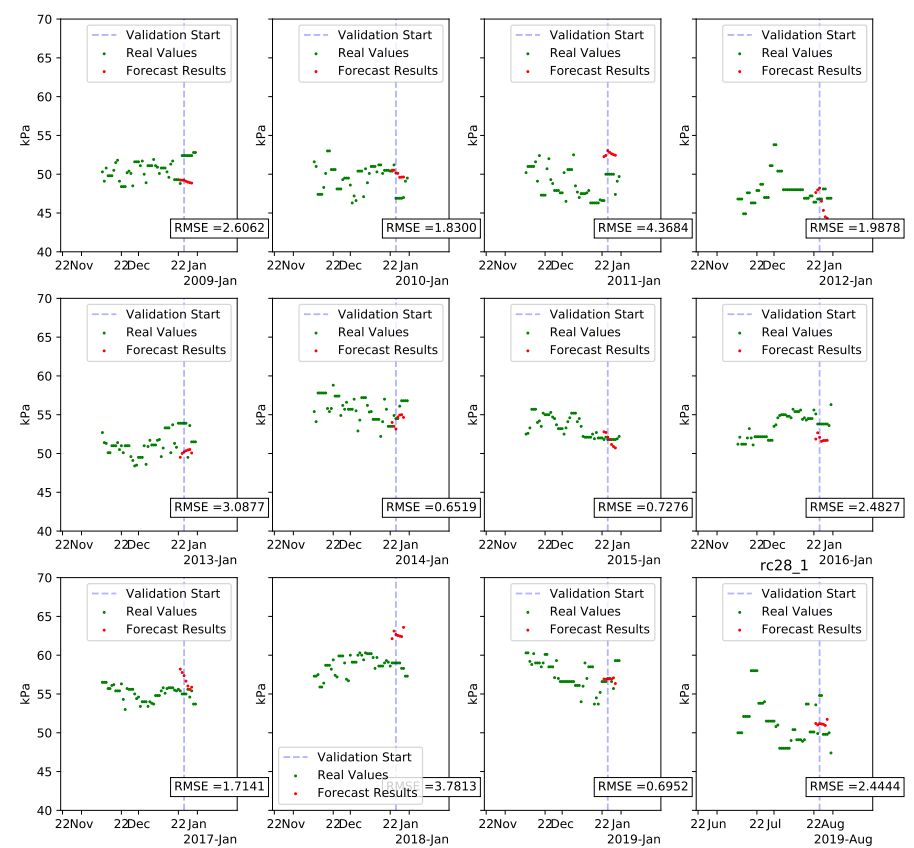

Figura 4.5: Predições no período de teste para cada período de validação pelo modelo reglin_1 


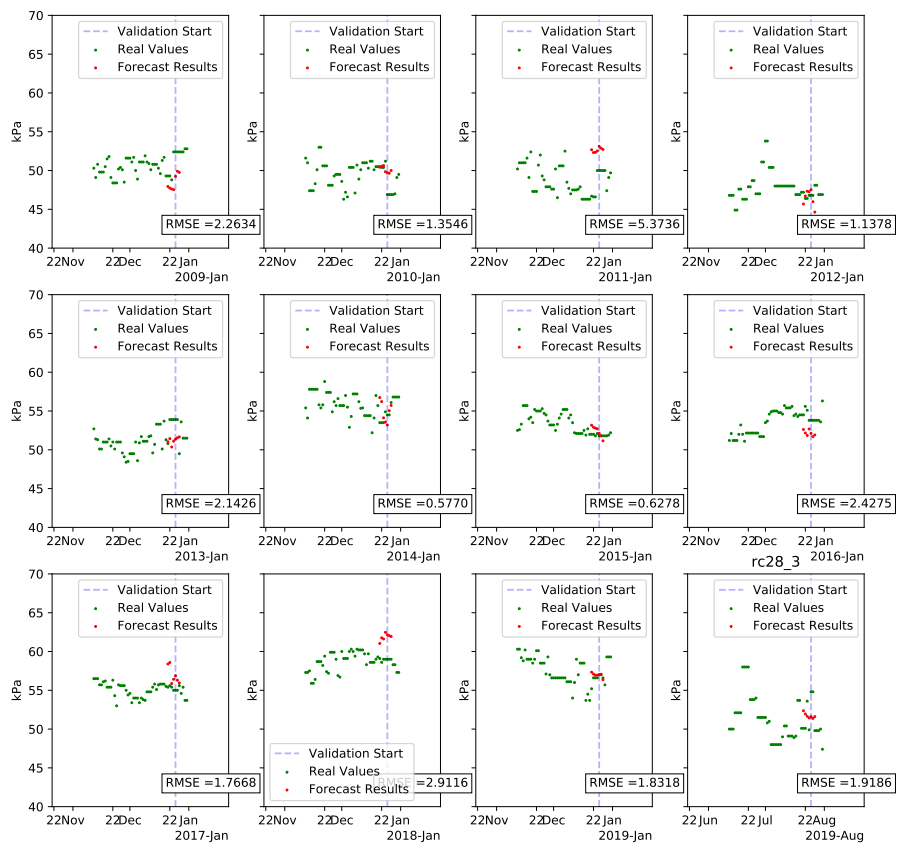

Figura 4.6: Predições no período de teste para cada período de validação pelo modelo reglin_3
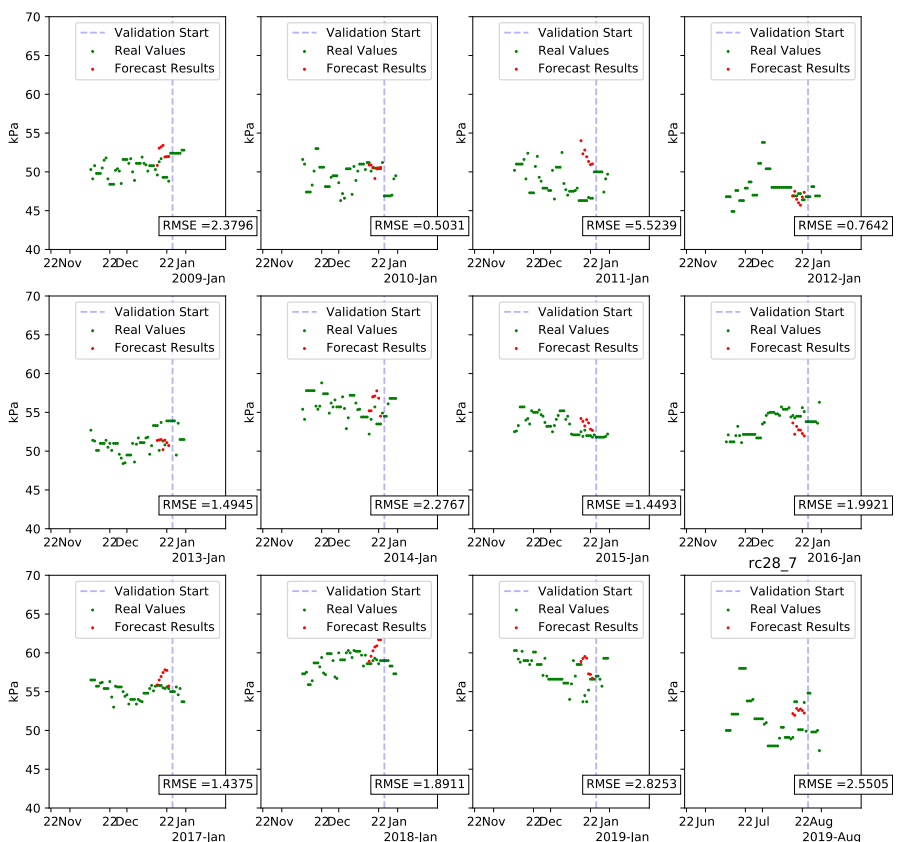

Figura 4.7: Predições no período de teste para cada período de validação pelo modelo reglin_7

Os modelos de regressão linear com janela móvel possuem uma boa assertividade para alguns casos possuem um erro sistemático para todo o mesmo dataset. Todos os modelos desse tipo falharam na tarefa de predição do ano de 2011, por exemplo. Agregando esses valores, podemos apresentar o RMSE médio para cada modelo para todo o dataset, para predições de $24 \mathrm{~h}$ e 7 dias. 


\begin{tabular}{|l|l|l|}
\cline { 2 - 2 } \multicolumn{1}{c|}{} & RMSE 24h & RMSE 7 dias \\
\hline reglin_1 & 1.66 & 2.19 \\
reglin_3 & 2.12 & 2.02 \\
\cline { 1 - 1 } reglin_7 & 2.09 & 1.63 \\
\cline { 1 - 1 } reglin_ew & 2.12 & 1.42 \\
\hline
\end{tabular}

Tabela 4.3: Valores agregados de RMSE para os modelos de Regressão Linear Dinâmica. Como esperado, o erro decresce a medida que mais variáveis são incorporadas ao modelo. O modelo corrigido tem o menor erro quadrático.

\subsection{Modelos de Deep Learning Bayesianos}

Usamos a implementação dos modelos DeepAR e DeepFactors da biblioteca GluonTS (AlEXANDrov et al., 2019). O modelo Uber foi implementado com as primitivas fornecidas pela biblioteca PyTorch (PAszke et al., 2017). De modo análogo ao modelo de Regressão Linear Dinâmica, para cada modelo de DL iremos treinar 3 versões distintas. Uma para cada conjunto de variáveis apresentado na Tabela 4.2. Para o modelo DeepAR, as versões treinadas serão chamadas de DeepAR_1, DeepAR_3 e DeepAR_7. Os outros modelos seguirão uma regra de nomeação análoga. Para possibilitar a comparação com o modelo de Regressão Linear Dinâmica, usaremos para esses modelos o mesmo tamanho do horizonte de predição, 7 dias. As mesmas séries temporais anuais são usadas para treinamento desses modelos, e os últimos 7 dias de cada ano serão usados como validação.

As Figuras 4.8,4.9 e 4.10 reportam as predições geradas por cada versão do modelo DeepAR, bem como o intervalo de confiança.
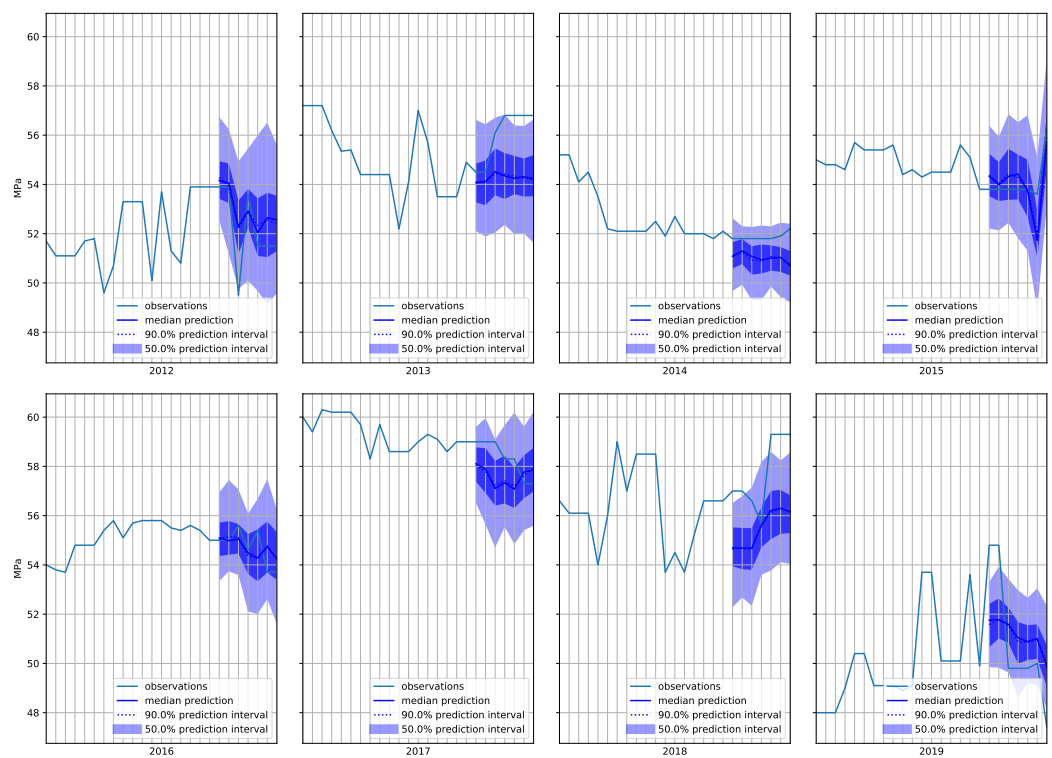

Figura 4.8: Predição do RC28 para todos os dados de validação para o modelo DeepAR_1 

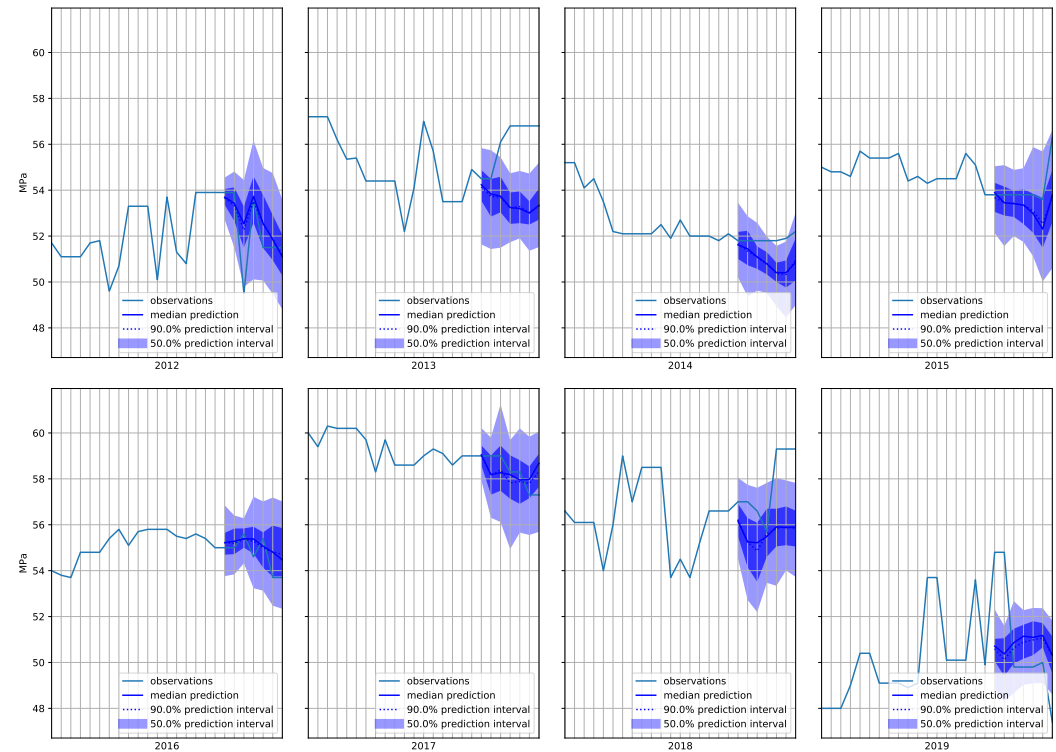

Figura 4.9: Predição do RC28 para todos os dados de validação para o modelo DeepAR_3
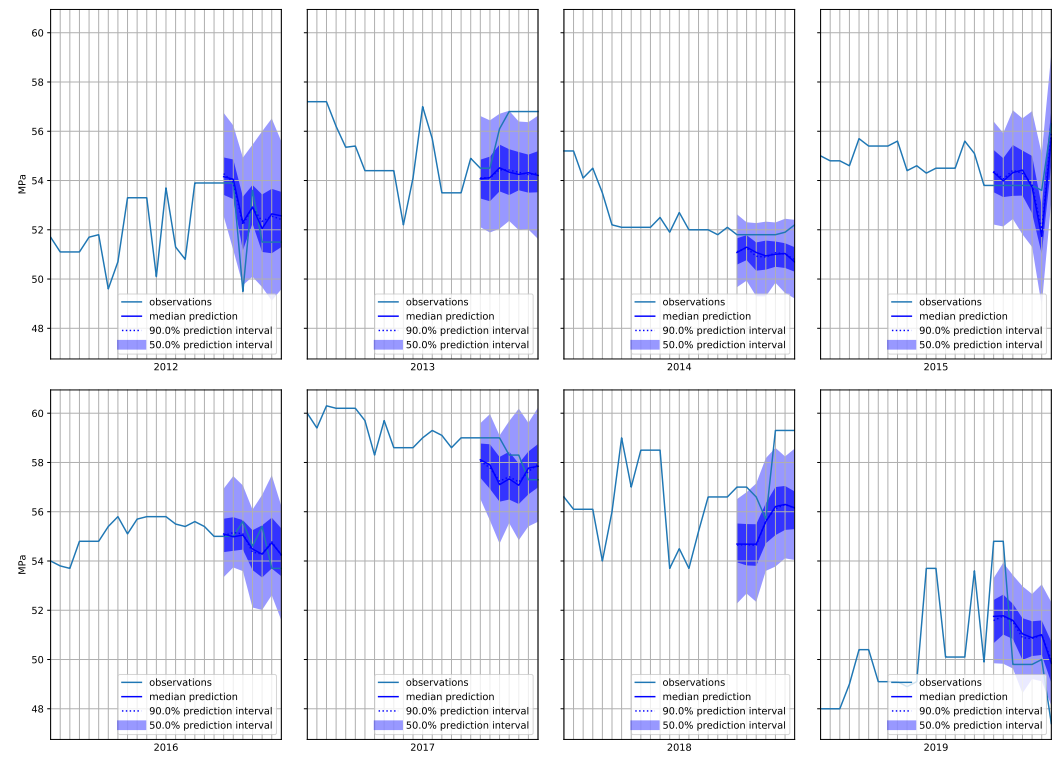

Figura 4.10: Predição do RC28 para todos os dados de validação para o modelo DeepAR_7

Os resultados reportados possuem uma boa cobertura probabilística e ao mesmo tempo uma acurácia pontual (a média das predições) com uma assertividade maior que os modelos de Aprendizado Automático. Os modelos de Aprendizado Profundo Bayesianos retornam, para cada predição, uma distribuição de probabilidade definida por média e variância, ou diversas realizações de uma distribuição desconhecida, da qual podemos estimar esses parâmetros. Com o desvio-padrão podemos reportar o risco das predições para diversos percentis, como explicado na Sessão 2.3.6. Os custos quantílicos dos modelos são reportados na Tabela 4.4. As coberturas (i.e. percentagem das predições dentro da margem de confiança retornada pelo modelo) de cada modelo são reportadas na Tabela 4.5. 


\begin{tabular}{|l|l|l|l|l|l|l|}
\cline { 2 - 7 } \multicolumn{1}{c|}{} & P50QL & \multicolumn{5}{l|}{ P90QL } \\
\cline { 2 - 7 } \multicolumn{1}{c|}{} & Factors_7 & Factors_3 & Factors_1 & Factors_7 & Factors_3 & Factors_1 \\
\hline 7d & 0.06 & 0.13 & 0.05 & 0.03 & 0.053 & 0.04 \\
\hline 24h & 0.06 & 0.13 & 0.05 & 0.03 & 0.053 & 0.04 \\
\hline & Uber_7 & Uber_3 & Uber_1 & Uber_7 & Uber_3 & Uber_1 \\
\hline 7d & 0.02 & 0.23 & 0.02 & 0.018 & 0.015 & 0.013 \\
\hline 24h & 0.01 & 0.21 & 0.01 & 0.012 & 0.010 & 0.008 \\
\hline & DeepAR_7 & DeepAR_3 & DeepAR_1 & DeepAR_7 & DeepAR_3 & DeepAR_1 \\
\hline 7d & 0.020 & 0.021 & 0.024 & 0.011 & 0.016 & 0.017 \\
\hline 24h & 0.020 & 0.021 & 0.024 & 0.011 & 0.016 & 0.017 \\
\hline
\end{tabular}

Tabela 4.4: Riscos-quantílicos para os percentis de 50\% e 90\% das distribuições das predições para os modelos de DL Bayesiano. Os menores riscos-quantílicos são fornecidos pelos modelos DeepAR $e$ Uber.

\begin{tabular}{|l|l|l|l|l|l|l|}
\cline { 2 - 7 } \multicolumn{1}{c|}{} & \multicolumn{4}{l|}{ Cobertura 0.5 } & Cobertura 0.9 \\
\cline { 2 - 7 } \multicolumn{1}{c|}{} & Factors_7 & Factors_3 & Factors_1 & Factors_7 & Factors_3 & Factors_1 \\
\hline 7d & 0.58 & 1 & 0.94 & 0.89 & 1 & 1 \\
\hline 24h & 0.58 & 1 & 0.94 & 0.89 & 1 & 1 \\
\hline & Uber_7 & Uber_3 & Uber_1 & Uber_7 & Uber_3 & Uber_1 \\
\hline 7d & 0.24 & 0.27 & 0.26 & 0.52 & 0.57 & 0.54 \\
\hline 24h & 0.28 & 0.28 & 0.28 & 0.71 & 0.71 & 0.71 \\
\hline & DeepAR_7 & DeepAR_3 & DeepAR_1 & DeepAR_7 & DeepAR_3 & DeepAR_1 \\
\hline 7d & 0.41 & 0.41 & 0.32 & 0.81 & 0.75 & 0.76 \\
\hline 24h & 0.41 & 0.41 & 0.32 & 0.81 & 0.75 & 0.76 \\
\hline
\end{tabular}

Tabela 4.5: Coberturas das predições probabilísticas para os quantis de $50 \%$ e $90 \%$ de confiança. Apesar de o modelo Deep Factors ser capaz de fornecer a maior cobertura, veremos mais adiante que a média das predições possui erros sensívelmente maiores que dos outros modelos.

As versões do modelo DeepAR possuem em média os menores riscos. O que indica que suas predições probabilísticas mais calibradas e com maior cobertura dos valores reais observados.

A Tabela 4.6 reporta o RMSE para cada modelo nos horizontes de tempo estudados na modelagem.

\section{Versão corrigida do modelo DeepAR}

Também corrigimos o modelo DeepAR_1 com o modelo DeepAR_7 de maneira análoga a Sessão 2.5.1, ao modelo corrigido damos o nome de DeepAR_ew. 


\begin{tabular}{|l|l|l|l|}
\cline { 2 - 4 } \multicolumn{1}{c|}{} & DeepFactors_7 & DeepFactors_3 & DeepFactors_1 \\
\hline 7d & 4.69 & 8.29 & 6.31 \\
\hline 24h & 3.42 & 6.52 & 4.89 \\
\hline & Uber_7 & Uber_3 & Uber_1 \\
\hline 7d & 2.70 & 2.51 & 2.21 \\
\hline 24h & 1.62 & 1.73 & 1.44 \\
\hline & DeepAR_7 & DeepAR_3 & DeepAR_1 \\
\hline 7d & 1.50 & 1.86 & 1.81 \\
\hline 24h & 1.87 & 1.68 & 1.66 \\
\hline
\end{tabular}

Tabela 4.6: Valores do RMSE para cada modelo nos horizonte de predição de 24 h e 7 dias. Os modelos Uber e DeepAR são sensivelmente melhores que os modelos Deep Factors. O modelo DeepAR gera predições mais estáveis para todas as tarefas de aprendizado.

Usando a média retornada para cada predição dos modelos DeepAR, é possível comparar o erro quadrático das predições de cada modelo. Iremos comparar esses resultados com os obtidos pelo modelo linear dinâmico.

\begin{tabular}{|l|l|l|}
\cline { 2 - 3 } \multicolumn{1}{c|}{} & RMSE $24 \mathrm{~h}$ & RMSE 7 dias \\
\hline reglin_1/DeepAR_1 & $1.66 / 1.68$ & $2.19 / 1.75$ \\
reglin_3/DeepAR_3 & $2.12 / 1.86$ & $2.02 / 1.68$ \\
\hline reglin_7/DeepAR_7 & $2.09 / 1.82$ & $1.63 / 1.42$ \\
reglin_ew/DeepAR_ew & $2.12 / 1.16$ & $1.42 / 1.12$ \\
\hline
\end{tabular}

Tabela 4.7: Valores do RMSE para cada modelo nos horizonte de predição de 24 h e 7 dias. Os modelos DeepAR consistentemente geram melhores predições agregando valores previstos por 7 dias após a implementação do modelo em produção.

Nota-se que as predições de $24 \mathrm{~h}$ são ruidosas para todos os modelos. Essa é a grandeza mais importante a ser prevista mas existe muita incerteza envolvida no problema e o modelo não tem acesso a todas as variáveis importantes da fábrica e ambiente que com certeza influenciam nos valores de resistência finais. 


\section{Capítulo 5}

\section{Conclusões}

Após realizados os experimentos, pode-se concluir que existe um ganho de qualidade e acurácia de predições no uso de modelos de Aprendizagem Profunda. Em particular modelos Bayesianos são capazes de gerar predições probabilísticas bastante versáteis para o controle de um processo industrial.

A limitação desse trabalho, porém, são a quantidade e o escopo dos dados fornecidos pela empresa Intercement. Pela análise ter sido levantada para dados de apenas uma fábrica os métodos possuem uma limitação intrínseca na garantia de resultados similares em outras fábricas, ou mesmo na fábrica de Cajati em outros períodos com anomalias diferentes das apresentadas pelos dados usados nesse trabalho.

Não obstante, esse trabalho mostra que, mesmo com uma quantidade menor de dados do que normalmente é possível para modelos de Aprendizado Profundo, é possível se obter uma melhor acurácia do que com modelos clássicos, e não precisamos abandonar as propriedades estatísticas desejáveis de modelos clássicos, pois com novas técnicas de aprendizado automático, podemos modelar também a incerteza das predições.

\subsection{Sugestões para Pesquisas Futuras}

Direções futuras de pesquisa incluem a aplicação desses modelos em dados de fábricas diferentes, para uma possível validação de resultados inter-fábricas. Existe também a ideia da aplicação de Transfer Learning. O uso de representações vetoriais aprendidas em um determinado conjunto de fábricas em alguma fábrica inédita. Isso permitiria que uma quantidade enorme de dados fosse aplicada para a criação de uma inteligência cujo domínio de aplicação seria estendido para fábricas do mundo todo.

Também existem os problemas técnicos para a implantação desses métodos no chão de fábrica. É necessário realizar a integração da pipeline de treinamento e inferência ao sistema de controle de dados das fábricas. Relacionado a isso também existe a possibilidade da criação de uma interface gráfica para que os resultados possam ser rapidamente acessados para um eventual uso para controle de todo o processo industrial. 


\section{.1 Hiper-parâmetros dos Modelos de Deep Lear- ning}

\begin{tabular}{|l|l|}
\hline Modelo & Deep_AR \\
\hline prediction_length & 7 \\
\hline num_cells & 200 \\
\hline num_layers & 2 \\
\hline context_length & 14 \\
\hline dropout_rate & 0.1 \\
\hline
\end{tabular}

Tabela 1: Parâmetros do modelo Deep_AR

\begin{tabular}{|l|l|}
\hline Modelo & Deep Factors \\
\hline prediction_length & 7 \\
\hline num_factors & 7 \\
\hline num_hidden_global & 1000 \\
\hline num_hidden_local & 100 \\
\hline num_cells & 200 \\
\hline num_layers & 1 \\
\hline context_length & 11 \\
\hline dropout_rate & 0.1 \\
\hline
\end{tabular}

Tabela 2: Parâmetros do modelo Deep Factors

\begin{tabular}{|l|l|}
\hline Modelo & Encoder-Decoder-Forecaster \\
\hline prediction_length & 7 \\
\hline embedding_size & 16 \\
\hline future_lookahead & 5 \\
\hline encoder_wdrop & 0.8 \\
\hline encoder_idrop & 0.8 \\
\hline decoder_wdrop & 0.8 \\
\hline decoder_idrop & 0.8 \\
\hline forecaster_drop & 0.8 \\
\hline forecaster_idrop & 0.8 \\
\hline
\end{tabular}

Tabela 3: Parâmetros do modelo Encoder-Decoder-Forecaster 


\section{Bibliografia}

[Neural Machine Translation - Tutorial ACL 2016 s.d.] Neural Machine Translation - Tutorial ACL 2016. https://sites.google.com/site/acl16nmt/. Accessed: 2018-08-27 (citado na pg. 24).

[Agency 2009] International Energy Agency. Cement Technology Roadmap: Carbon Emissions Reductions up to 2050. 2009, pg. 36. DoI: https://doi.org/https://doi.org/10. 1787/9789264088061-en. URL: https://www.oecd-ilibrary.org/content/publication/ 9789264088061-en (citado nas pgs. 1, 3).

[Asteriou e Hall 2016] Dimitrios Asteriou e Stephen Hall. "Arima models and the box-jenkins methodology”. Em: jan. de 2016, pgs. 275-296. IsBN: 978-1-137-41546-2. DOI: 10.1057/978-1-137-41547-9_13 (citado na pg. 2).

[Alexandrov et al. 2019] Alexander Alexandrov et al. GluonTS: Probabilistic Time Series Models in Python. 2019. arXiv: 1906.05264 [cs.LG] (citado na pg. 49).

[BARber 2012] D. BARber. Bayesian Reasoning and Machine Learning. Cambridge University Press, 2012 (citado nas pgs. 2, 13).

[Flunkert et al. 2017] Valentin Flunkert, David Salinas e Jan Gasthaus. "Deepar: probabilistic forecasting with autoregressive recurrent networks". Em: arXiv preprint arXiv:1704.04110 (2017) (citado nas pgs. 2, 14, 30).

[Y. GAL 2016] Yarin GAL. "Uncertainty in Deep Learning”. Tese de dout. University of Cambridge, 2016 (citado nas pgs. 2, 25).

[Z. GAL Y. 2016] Zoubin GAL Yarin. "Dropout as a bayesian approximation: representing model uncertainty in deep learning". Em: Proceedings of the 33rd International Conference on International Conference on Machine Learning - Volume 48. ICML'16. New York, NY, USA: JMLR.org, 2016, pgs. 1050-1059. URL: http://dl.acm.org/ citation.cfm?id=3045390.3045502 (citado nas pgs. 25-27).

[García-Casillas et al. 2007] P. E. García-Casillas, C. A. Martinez, H. Camacho Montes e A. García-Luna. "Prediction of portland cement strength using statistical methods". Em: Materials and Manufacturing Processes 22.3 (2007), pgs. 333-336. DOI: 10.1080/10426910701190352. eprint: https:// doi . org/ 10 . 
1080/10426910701190352. URL: https://doi.org/10.1080/10426910701190352 (citado na pg. 1).

[Goodfellow et al. 2016] Ian Goodfellow, Yoshua Bengio e Aaron Courville. Deep Learning. http://www.deeplearningbook.org. MIT Press, 2016 (citado nas pgs. 2, $9-12,14,16,17,20,23,24,39,41,44)$.

[Green et al. 2011] Kesten Green, Andreas Graefe e J Armstrong. "Forecasting principles”. Em: out. de 2011, pgs. 527-534. ISBN: 978-3-642-04897-5. DOI: 10 . 1007/978-3-642-04898-2_257 (citado na pg. 2).

[Hochreiter e Schmidhuber 1997] Sepp Hochreiter e Jürgen Schmidhuber. "Long short-term memory”. Em: 9 (dez. de 1997), pgs. 1735-80 (citado na pg. 22).

[Hornik et al. 1989] Kurt Hornik, Maxwell Stinchcombe e Halbert White. "Multilayer feedforward networks are universal approximators". Em: Neural networks 2.5 (1989), pgs. 359-366 (citado na pg. 15).

[Khashei e Bijari 2010] Mehdi Khashei e Mehdi Bijari. "An artificial neural network (p,d,q) model for timeseries forecasting". Em: Expert Systems with Applications 37.1 (2010), pgs. 479-489. ISSN: 0957-4174. DOI: https://doi.org/10.1016/j.eswa.2009. 05.044. URL: http://www.sciencedirect.com/science/article/pii/S0957417409004850 (citado na pg. 2).

[Koopmans 1974] L.H. Koopmans. The Spectral Analysis of Time Series. Probability and mathematical statistics, 22. Acad. Press, 1974. ISBN: 9780124192508. uRL: https: //books.google.com.br/books?id=6ttQAAAAMAAJ (citado na pg. 7).

[LAPTEV et al. 2017] Nikolay Laptev, Jason Yosinski, Li Erran Li e Slawek Smyl. "Timeseries extreme event forecasting with neural networks at uber”. Em: 2017 (citado nas pgs. 2, 13, 27-29).

[MARino et al. 2016] Daniel L. Marino, Kasun Amarasinghe e Milos Manic. "Building energy load forecasting using deep neural networks". Em: CoRR abs/1610.09460 (2016). arXiv: 1610.09460. URL: http://arxiv.org/abs/1610.09460 (citado na pg. 2).

[McElreath 2016] R. McElreath. Statistical Rethinking: A Bayesian Course with Examples in $R$ and Stan. Chapman \& Hall/CRC Texts in Statistical Science. CRC Press, 2016. ISBN: 9781482253467. uRL: https://books.google.com.br/books?id= mDo0CwAAQBAJ (citado na pg. 12).

[Murphy 2013] Kevin P. Murphy. Machine learning : a probabilistic perspective. Cambridge, Mass. [u.a.]: MIT Press, 2013. uRL: https://www.amazon.com/MachineLearning-Probabilistic-Perspective-Computation/dp/0262018020/ref $=$ sr_1_2? ie $=$ UTF8\&qid $=1336857747 \& s r=8-2$ (citado na pg. 11). 
[Maddix et al. 2018] Danielle C Maddix, Yuyang Wang e Alex Smola. "Deep factors with gaussian processes for forecasting”. Em: arXiv preprint arXiv:1812.00098 (2018) (citado nas pgs. 2, 10, 32).

[PAszke et al. 2017] Adam PAszke et al. "Automatic differentiation in pytorch". Em: (2017) (citado na pg. 49).

[Robles et al. 2008] Luis A. Robles et al. "A hybrid arima and artificial neural networks model to forecast particulate matter in urban areas: the case of temuco, chile". Em: Atmospheric Environment 42.35 (2008), pgs. 8331-8340. ISSN: 1352-2310. DOI: https://doi.org/10.1016/j.atmosenv.2008.07.020. URL: http://www.sciencedirect. com/science/article/pii/S1352231008006523 (citado na pg. 2).

[Rasmussen e Williams 2005] Carl Edward Rasmussen e Christopher K. I. Williams. Gaussian Processes for Machine Learning (Adaptive Computation and Machine Learning). The MIT Press, 2005. IsBN: 026218253X (citado na pg. 33).

[Siami-Namini e Namin 2018] Sima Siami-Namini e Akbar Siami Namin. "Forecasting economics and financial time series: ARIMA vs. LSTM". Em: CoRR abs/1803.06386 (2018). arXiv: 1803.06386. uRL: http://arxiv.org/abs/1803.06386 (citado na pg. 8).

[TAffese e Sistonen 2017] Woubishet Zewdu TAffese e Esko Sistonen. "Machine learning for durability and service-life assessment of reinforced concrete structures: recent advances and future directions”. Em: Automation in Construction 77 (2017), pgs. 1-14. ISSN: 0926-5805. DOI: https://doi.org/10.1016/j.autcon.2017.01.016. URL: http://www.sciencedirect.com/science/article/pii/S0926580517300559 (citado na pg. 1).

[Tsamatsoulis 2014] Dimitris Tsamatsoulis. "Application of the static and dynamic models in predicting the future strength of portland cements”. Em: set. de 2014. DOI: 10.1109/MCSI.2014.38 (citado na pg. 1).

[Tsamatsoulis 2015] Dimitris Tsamatsoulis. "Optimizing the cement compressive strength prediction by applying coupled linear models”. Em: jan. de 2015 (citado nas pgs. 7, 17, 18, 46, 47).

[Zhang et al. 2012] Q. Zhang, B. YAng, L. Wang e F. Zhu. "Predicting cement compressive strength using double-layer multi-expression programming”. Em: 2012 Fourth International Conference on Computational and Information Sciences. Ago. de 2012, pgs. 94-97. DoI: 10.1109/ICCIS.2012.207 (citado na pg. 1). 
